\title{
HRB-22 Preirradiation Thermal Analysis
}

\author{
R. Acharya \\ K. Sawa
}


This report has been reproduced directly from the best available copy.

Available to DOE and DOE contractors from the Office of Scientific and Technical Information, P.O. Box 62, Oak Ridge, TN 37831; prices available from (615) 576-8401, FTS 626-8401.

Available to the public from the National Technical Information Service, U.S. Department of Commerce, $\mathbf{5 2 8 5}$ Port Royal Rd., Springfield, VA 22161.

This report was prepared as an account of work sponsored by an agency of the United States Government. Neither the United States Government nor any agency thereof, nor any of their employees, makes any warranty, express or implied, or assumes any legal liability or responsibility for the accuracy, completeness, or usefulness of any information, apparatus, product, or process disclosed, or represents that its use would not infringe privately owned rights. Reference herein to any specific commercial product, process, or service by trade name, trademark, manufacturer, or otherwise, does not necessarily constitute or imply its endorsement, recommendation, or favoring by the United States Government or any agency thereof. The views and opinions of authors expressed herein do not necessarily state or reflect those of the United States Government or any agency thereof. 
HRB-21 PREIRRADIATION THERMAL ANALYSIS

R. Acharya and K Sawa

Date Published: May 1995

Prepared for the U.S. Department of Energy

Office of Advanced Reactor Programs

AF 2050100

Prepared by the OAK RIDGE NATIONAL LABORATORY

Oak Ridge, Tennessee

managed by

MARTIN MARIETTA ENERGY SYSTEMS, INC.

for the

U.S. DEPARTMENT OF ENERGY

under contract DE-ACO5-84OR21400 


\section{DISCLAIMER}

Portions of this document may be illegible in electronic image products. Images are produced from the best available original document. 
LIST OF TABLES $\ldots \ldots \ldots \ldots \ldots \ldots \ldots \ldots \ldots \ldots \ldots \ldots \ldots \ldots \ldots \ldots$

LIST OF FIGURES $\ldots \ldots \ldots \ldots \ldots \ldots \ldots \ldots \ldots \ldots \ldots \ldots \ldots \ldots \ldots \ldots$

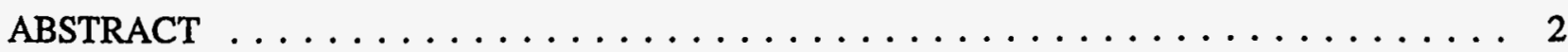

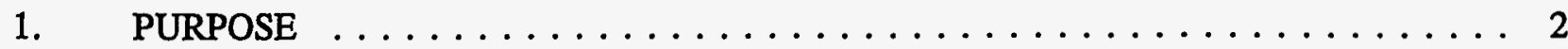

2. CAPSULE DESIGN FEATURES $\ldots \ldots \ldots \ldots \ldots \ldots \ldots \ldots \ldots \ldots \ldots$

3. OPERATIONAL REQUIREMENTS $\ldots \ldots \ldots \ldots \ldots \ldots \ldots \ldots \ldots \ldots$

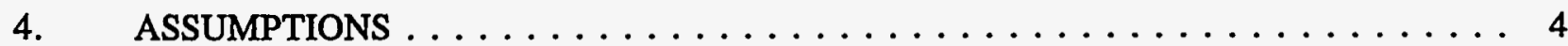

5. JUSTIFICATION OF ASSUMPTIONS $\ldots \ldots \ldots \ldots \ldots \ldots \ldots \ldots$

6. EXPECTED OPERATING CONDITIONS $\ldots \ldots \ldots \ldots \ldots \ldots \ldots \ldots \ldots \ldots$

7. THERMAL ANALYSIS $\ldots \ldots \ldots \ldots \ldots \ldots \ldots \ldots \ldots \ldots \ldots \ldots \ldots \ldots$

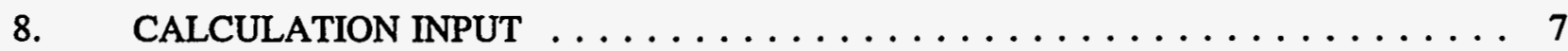

9. THERMAL ANALYSIS MODEL $\ldots \ldots \ldots \ldots \ldots \ldots \ldots \ldots \ldots$

10. RESULTS OF THE THERMAL ANALYSIS $\ldots \ldots \ldots \ldots \ldots \ldots \ldots \ldots$

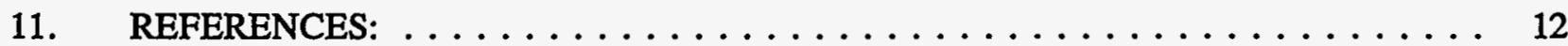

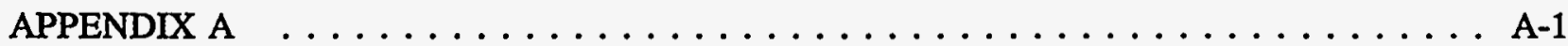

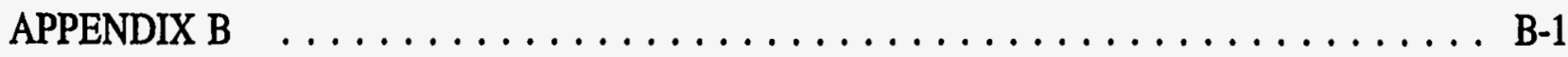




\section{LIST OF TABLES}

1. Time Dependent Power Density in the Fuel Compacts $\ldots \ldots \ldots \ldots \ldots$

2. Predicted Dimensional Changes of Fuel Compact and Graphite Fuel Body

During Irradiation $\ldots \ldots \ldots \ldots \ldots \ldots \ldots \ldots \ldots \ldots \ldots \ldots \ldots \ldots \ldots$

\section{LIST OF FIGURES}

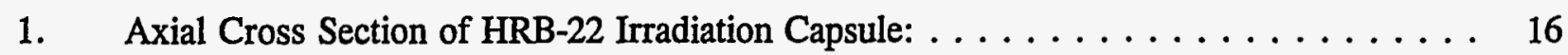

2. Radial Cross Section of HRB-22 Irradiation Capsule: $\ldots \ldots \ldots \ldots \ldots \ldots \ldots .17$

3. Predicted Total Power History for Individual Compacts: $\ldots \ldots \ldots \ldots \ldots \ldots$

4. Predicted Burnup for Individual Compacts $\ldots \ldots \ldots \ldots \ldots \ldots \ldots \ldots \ldots$

5. Predicted Fast Fluence for Individual Compacts $\ldots \ldots \ldots \ldots \ldots \ldots \ldots \ldots$

6. Thermal Conductivity of Unirradiated Grade 2020 Graphite . . . . . . . . . 19

7. Design Curves for Change in Room temperature Thermal Resistivity for Grade 2020 Graphite as a function of Irradiation Conditions $\ldots \ldots \ldots \ldots \ldots \ldots \ldots$

8. Fluence Dependance of Dimensional Change of Grade 2020 Graphite . . . . . . . 21

9. Evolution of Cold Gap Between the Fuel Compact and the Graphite Fuel Body . . . . 22

10. Evolution of The Cold Gap Between the Graphite Fuel Body and the Primary Inconel Pressure Vessel ........................ 22

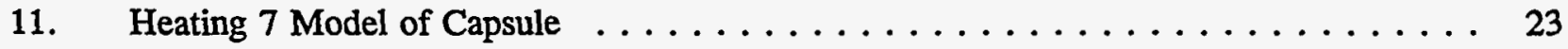

12. Heating 7 Model of Bottom of Capsule $\ldots \ldots \ldots \ldots \ldots \ldots \ldots \ldots \ldots \ldots$

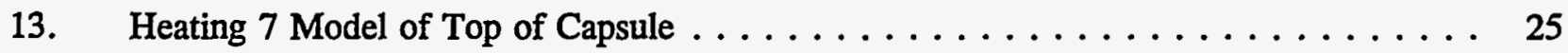

14. Beginning of Cycle 1 Axial Temperature Distribution ............. 26

15. Beginning of Cycle 1 Radial Temperature Distribution $\ldots \ldots \ldots \ldots \ldots \ldots 26$

16. End of Cycle 1 Axial Temperature Distribution ............... 27

17. End of Cycle 1 Radial Temperature Distribution $\ldots \ldots \ldots \ldots \ldots \ldots \ldots \ldots 27$

18. Beginning of Cycle 2 Axial Temperature Distribution $\ldots \ldots \ldots \ldots \ldots \ldots \ldots 28$

19. Beginning of Cycle 2 Radial Temperature Distribution $\ldots \ldots \ldots \ldots \ldots \ldots \ldots$

20. End of Cycle 2 Axial Temperature Distribution . . . . . . . . . . . . . 29

21. End of Cycle 2 Radial Temperature Distribution . . . . . . . . . . . . 29

22. Beginning of Cycle 3 Axial Temperature Distribution $\ldots \ldots \ldots \ldots \ldots \ldots \ldots$

23. Beginning of Cycle 3 Radial Temperature Distribution $\ldots \ldots \ldots \ldots \ldots \ldots$ 
24. End of Cycle 3 Axial Temperature Distribution . . . . . . . . . . . . 31

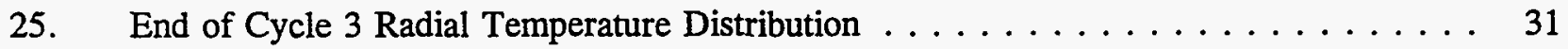

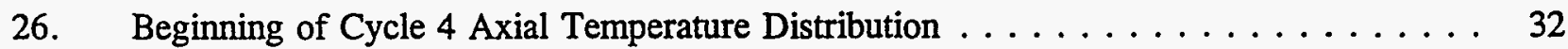

27. Beginning of Cycle 4 Radial Temperature Distribution $\ldots \ldots \ldots \ldots \ldots$

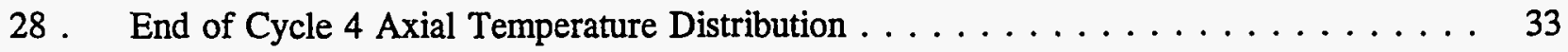

29. End of Cycle 4 Radial Temperature Distribution $\ldots \ldots \ldots \ldots \ldots \ldots$

30. 3-D representation of temperature fields in the capsule at end of cycle $1 \ldots 34$

31. Comparison of temperature profiles through the primary and secondary pressure

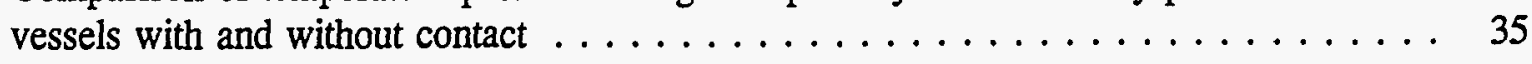

32. Predicted maximum temperature of the inner surface of the primary pressure

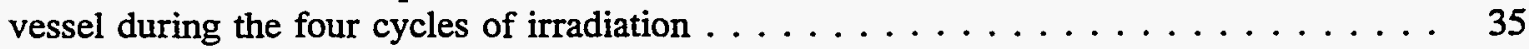




\begin{abstract}
This report describes the preirradiation thermal analysis of the HRB-22 capsule designed for irradiation in the removable beryllium (RB) position of the High Flux Isotope Reactor (HFIR) at Oak Ridge National laboratory (ORNL). CACA-2 a heavy isotope and fission product concentration calculational code for experimental irradiation capsules was used to determine time dependant fission power for the fuel compacts. The Heat Engineering and Transfer in Nine Geometries (HEATING) computer code, version 7.2, was used to solve the steady-state heat conduction problem. The diameters of the graphite fuel body that contains the compacts and the primary pressure vessel were selected such that the requirements of running the compacts at an average temperature of $\leq 1250 \mathrm{C}$ and not exceeding a maximum fuel temperature of $1350 \mathrm{C}$ was met throughout the four cycles of irradiation.
\end{abstract}

\title{
1. PURPOSE
}

The primary purpose of this thermal analysis to make a preirradiation prediction of the in-reactor performance of the HRB-22 irradiation capsule. This performance prediction effort will be used to complete the capsule design, provide support to the capsule safety analysis and finally to help in the day to day operation of the irradiation capsule.

HRB-22 capsule is designed to irradiate the Japanese fuel compacts (advanced fuel for the HTTR) in the HFIR (High Flux Isotope Reactor) at ORNL. The irradiation will be conducted in the Removable Beryllium Facility (RB) for four reactor operating cycles. The capsule design details, operating conditions, fission power, gamma heating and the pre-irradiation thermal analysis are documented here. This analysis provides a prediction of the thermal and neutronic performance of the capsule and will be used in the day to day operation of the capsule.

\section{CAPSULE DESIGN FEATURES}

The design of the HRB-22 capsule consists of a doubly contained, single purge cell with 12 fuel 
compacts contained in a graphite fuel body. The fuel compacts are annular, with an outside diameter of $26.05 \mathrm{~mm}$, inside diameter of $10 \mathrm{~mm}$ and a height of $39 \mathrm{~mm}$. The compacts will be enclosed in a graphite fuel body fabricated from grade 2020 graphite. The outside diameter of the graphite fuel body is about $38 \mathrm{~mm}$. Grade 2020 graphite is a fine grain graphite manufactured by Stackpole Carbon Company. The axial cross section of the capsule internal design showing, the position of the compacts is shown in Figure 1. Compacts one through six are located in the top half of the graphite fuel body and are above the reactor axial midplane, with compact six being near the axial midplane. Similarly compacts seven through 12 are located below the axial midplane of the reactor core. Compact pairs 1,12 and 2 , 11 , etc., operate under nearly identical conditions of power, flux and temperature because of the symmetry.

The fuel body with fuel compacts will be placed inside a double walled inconel-718 pressure vessel. A typical radial cross section of the capsule is shown in Figure 2. The temperature of the graphite fuel body will be monitored by thermocouples (TCATs) at axial positions corresponding to approximately the axial midpoints of each fuel compact. The radial locations of the thermocouples with respect to the fuel compacts are shown in Figure 2. The capsule includes facility for introduction of purge gas (helium neon gas mixture). The gap between the graphite fuel body and the inconel pressure vessel is filled with flowing helium and neon purge gas mixture. The concentration of neon in helium is adjusted to control the temperature drop in the gas gaps. The same gas mixture occupies the gap between the fuel compact and the graphite fuel body. The purge gas will also be used to measure the fission gas release on-line.

\section{OPERATIONAL REQUIREMENTS}

The capsule shall be irradiated in the RB position of HFIR for a total of four cycles. For purposes of this preirradiation thermal analysis, each reactor cycle is assumed to last 22 days to be followed by a reactor shutdown period of five days. The desired fuel compact volume average operating temperature is $1250 \mathrm{C}$. The maximum fuel compact operating temperature shall not exceed $1350 \mathrm{C}$. The fuel loading in the compacts is fixed and cannot be used to control the compact power and compact operating temperature. The fuel loading in all compacts is the same. Adjustment of the gas gap between the graphite fuel body and the primary pressure vessel and adjusting the concentration of neon in helium in the gas gap are the only available methods for controlling the operating temperature of individual 
compacts. Therefore, preirradiation as fabricated gas gaps are extremely important in the thermal performance of the capsule during the irradiation.

\section{ASSUMPTIONS}

There are only two assumptions of importance that are required for the analysis of the capsule irradiation and thermal performance. They are:

1. The compact power densities during the irradiation in the RB position of HFIR can be adequately described and calculated by the CACA-2 computer code (Ref. 1).

2. The dimensional change of grade $\mathbf{2 0 2 0}$ graphite is adequately described in the plot from Figure 7. This plot shows measured data from various experiments in HFIR. The first data point is for a fast fluence $(0.18 \mathrm{MeV})$ of about $12 \times 10^{25} \mathrm{n} / \mathrm{m}^{2}$. The maximum fluence experienced by the graphite fuel body in this experiment is less that $3.3 \times 10^{25} \mathrm{n} / \mathrm{m}^{2}$. A linear dependance of the dimensional change from zero fluence to the maximum fluence is assumed.

\section{JUSTIFICATION OF ASSUMPTIONS}

CACA-2 has been successfully used for predicting the irradiation performance of many fuel irradiation capsules in HFIR. As an example, the fission power generation in the HRB-21 compacts were predicted using CACA-2 and a completely independent analysis method using the measured thermocouple temperatures and detailed capsule geometry. The two methods yielded results which are within $5 \%$ of each other for most of the irradiation test (Ref. HRB-21 Final report).

The database on irradiation induced dimensional change (Ref. 6) for grade 2020 graphite is limited. This is especially true for the temperature dependance of the dimensional change as a function of fluence. The only available data is for irradiation at $600 \mathrm{C}$. The graphite fuel body in the HRB-22 irradiation capsule operates at temperatures ranging from 500 to $900 \mathrm{C}$ during the test. Using data gathered at a temperature of $600 \mathrm{C}$ to predict the performance at a range of temperatures requires justification. As a guide to understanding the temperature dependance, the more extensive database on $\mathrm{H}-451$ grade graphite dimensional change as a function of fast fluence was consulted. In this case for the 
range of fluences of interest, the dimensional change at temperatures of 600 and $800 \mathrm{C}$ are nearly the same. In addition the shape of the fluence dependance is nearly linear. Based on this information the confidence level in using the available data on grade 2020 graphite is high.

\section{EXPECTED OPERATING CONDITIONS}

The thermal design of the capsule requires a detailed knowledge of the geometry and operating conditions. The power generation in each component of the capsule as a function of time must be known along with the dimensions for the thermal analysis. Power is generated in the compacts by fission and by gamma heating. Gamma heating generates power in all the rest of capsule components.

The power generation by fission in each compact is calculated using CACA-2 computer code (Ref. 1). This computer code calculates the compact fission power density as a function time based on initial fuel loading, location of the capsule in the reactor, location of the compact in the capsule and the assumed reactor operating power. The U-235 and U-238 loadings for each compact were obtained from the quality assurance (QA) data package (Ref. 2). A HFIR cycle length of 22 days of operation followed by five days of shutdown was assumed in this analysis. The reactor is assumed to operate at $85 \%$ of full design power of $100 \mathrm{MW}(\mathrm{t})$. The input data set for the CACA-2 analysis is given in Appendix A. This data set is annotated for ease of understanding.

The CACA-2 analysis provides individual compact fission power density as a function of time. There is an additional contribution from gamma heating in the compacts. The gamma heating contribution to the compact power density ranges from 13 to $22 \mathrm{~W} / \mathrm{cc}$ depending on the axial position of the compact in the capsule. The data for computing the gamma heating values were obtained from Reference 3 . The fission plus gamma heating power densities for the four cycles of operation in the RB position in HFIR are listed in Table 1 and plotted for each compact in Figure 3. 
Table 1. Time Dependent Power Density of Fuel Compacts

\begin{tabular}{|c|c|c|c|c|c|c|c|}
\hline & \multicolumn{6}{|c|}{ COMPACTS } \\
\hline & & $\overline{1}$ & 2 & 3 & 4 & 5 & 6 \\
\hline & Time (d) & \multicolumn{6}{|c|}{ Power Density (W/cc) } \\
\hline \multirow{8}{*}{$\begin{array}{l}\text { Fission } \\
\text { Power }\end{array}$} & $\overline{0}$ & 36 & 53 & 69 & 86 & 97 & 104 \\
\hline & $\overline{22}$ & 67 & 82 & 91 & 108 & $\overline{101}$ & 105 \\
\hline & 27 & 40 & 58 & 77 & 96 & 109 & 117 \\
\hline & 49 & 68 & 81 & 89 & 103 & 97 & 99 \\
\hline & 54 & 40 & 58 & 75 & 92 & 105 & $\overline{111}$ \\
\hline & 76 & 66 & 78 & 85 & 98 & 91 & 94 \\
\hline & 81 & 39 & 56 & 72 & 88 & 99 & 105 \\
\hline & $\overline{103}$ & 65 & $\overline{75}$ & 81 & 93 & 87 & 89 \\
\hline \multicolumn{2}{|c|}{ Gamma Heat } & 13 & 16 & 18 & 20 & 21 & 22 \\
\hline \multirow{8}{*}{$\begin{array}{l}\text { Total } \\
\text { Power }\end{array}$} & 0 & 49 & 69 & 87 & 105 & 119 & 126 \\
\hline & $\overline{22}$ & 80 & 97 & 109 & 128 & 123 & 127 \\
\hline & 27 & 53 & 74 & 95 & 116 & 131 & 139 \\
\hline & 49 & 81 & 96 & 107 & 123 & 118 & $\overline{121}$ \\
\hline & 54 & 53 & 73 & 93 & 112 & 126 & 133 \\
\hline & 76 & 80 & 93 & $\overline{102}$ & 118 & 112 & 116 \\
\hline & $\overline{81}$ & 52 & 71 & 90 & 107 & 120 & 127 \\
\hline & 103 & 78 & 90 & 99 & 113 & 108 & $\overline{111}$ \\
\hline
\end{tabular}

Please note that the power density is the highest at the beginning of each irradiation cycle. The compacts at or near the end of the capsules undergo the greatest change in fission power production during a given cycle. The compacts in the middle of the capsule operate at approximately constant power throughout the cycle. This behavior is the result of the movement of reactor control blades during each cycle. The peak power density in the compacts occurs at the beginning of the second cycle of operation.

CACA-2 analysis also computes burnup as a function of irradiation time. The calculated burnup for individual compacts are shown in Figure 4. The compacts in the center of the capsule (6 and 7) reach a burnup of about $9 \%$ and the end compacts (1 and 12) accumulate a burnup of $4 \%$.

The time dependance of fast fluence for individual compacts is shown in Figure 5. The maximum 
fast fluence (compact 6 and 7 ) is about $3.14 \times 10^{25} \mathrm{n} / \mathrm{m}^{2}$. The minimum fast fluence is $1.57 \times 10^{25} \mathrm{n} / \mathrm{m}^{2}$ for compacts 1 and 12 .

\section{THERMAL ANALYSIS}

The thermal analysis requires capsule dimensions, operating power history and materials' behavior database. The capsule dimensions were obtained from ORNL drawings X3E0126730220 through $\mathrm{X} 3 \mathrm{E} 0126730226$. The power densities as a function of time were obtained from the CACA-2 analysis described above. The material's database, i.e., thermal conductivities, thermal expansion coefficients, irradiation induced changes in dimensions and physical properties along with sources for the database is described below.

\section{CALCULATION INPUT}

This section lists all the input data, including material property correlations, data sources, basic capsule dimensions and the actual computer program input files.

\section{Fuel Compact Thermal Conductivity}

The raw data on the thermal conductivity of unirradiated fuel compacts (Ref. 4) was fitted to a second order polynomial as follows:

$$
K_{u n}=a * T^{2}+b * T+C
$$

Where,

$$
\begin{aligned}
& \mathrm{T} \quad \text { - } \quad \text { is the temperature in degrees Celsius } \\
& \text { a - } \quad 1.014 \mathrm{E}-07 \\
& \text { b - 2.919E-04 } \\
& \text { c - } 0.3896 \\
& \text { and } \\
& K_{m} \text { has units of } W /(\mathrm{cm} . K)
\end{aligned}
$$


The best fit to raw data on the fast neutron fluence dependence of the thermal conductivity of the fuel compact (Ref. 4) is given by:

$$
K_{i r I}=K_{u n} *\left[d *(\Phi t)^{2}+e * \Phi t+1\right]
$$

Where,

Фt - is the fast neutron fluence in units of $10^{25} \mathrm{n} / \mathrm{m}^{2}$

d $\quad$ - $\quad 5.314 \mathrm{E} 02$

e $\quad-\quad 0.2931$

\section{Euel Compact Thermal Expansion}

The thermal expansion coefficient of fuel compact (Ref. 4) is $2.45 \mathrm{E}-06 \mathrm{~K}^{-1}$. It is assumed that irradiation does not change the thermal expansion coefficient of the fuel compact.

\section{Fuel Compact Irradiation Induced Dimensional Change}

The best fit to the raw data on irradiation induced dimensional change of the fuel compact (Ref. 4) is given by:

$$
\frac{\Delta d}{d}=f * \Phi t^{2}+g * \Phi t
$$

\section{Where,}

$\Delta \mathrm{d} / \mathrm{d} \quad$ - $\quad$ is the fractional change in the radial dimension

$\Phi \mathrm{t} \quad$ - $\quad$ is the fast neutron fluence in units of $10^{25} \mathrm{n} / \mathrm{m}^{2}$

f $\quad-\quad 1.740 \mathrm{E}-03$

g - $\quad-1.006 \mathrm{E}-02$

Euel Compact Emissivity

The emissivity of the fuel compact is assumed to be 0.9 . 
Thermal Conductivity of Grade 2020 Graphite

Thermal conductivity of unirradiated grade 2020 graphite (Ref. 5) along the radial direction of the $\log$ is shown in Figure 6 . The change in the thermal conductivity of irradiated graphite at irradiation temperature is given by:

$$
\frac{1}{K_{i}(T)}=\frac{1}{K_{0}(T)}+\frac{F}{K_{0}(295 K)}
$$

Where,

$\mathrm{K}_{\mathrm{i}}(\mathrm{T}) \quad$ - $\quad$ Thermal conductivity of irradiated graphite at temperature $\mathrm{T}(\mathrm{K})$

$\mathrm{K}_{0}(\mathrm{~T}) \quad$ - $\quad$ Thermal conductivity of unirradiated graphite at temperature $\mathrm{T}(\mathrm{K})$

$\mathrm{K}_{\mathrm{o}}(295 \mathrm{~K}) \quad$ - $\quad$ Thermal conductivity of unirradiated graphite at temperature $295 \mathrm{~K}$

F $\quad$ - The fractional increase in thermal resistivity due to neutron irradiation as shown in Figure 7.

\section{Thermal Expansion of Grade 2020 Graphite}

The thermal expansion coefficient of grade 2020 graphite in the radial direction (Ref. 5) is $3.2 \mathrm{E}-06 \mathrm{~K}^{-1}$. The thermal expansion coefficient does not change with irradiation.

Irradiation Induced Dimensional Change of Grade 2020 Graphite

Irradiation induced dimensional change of grade 2020 graphite is shown in Figure 8 from reference 6. The measured data is for fluences greater than $10 \times 10^{25} \mathrm{n} / \mathrm{m}^{2}$, whereas the need is for data for fluences up to $3.14 \times 10^{25} \mathrm{n} / \mathrm{m}^{2}$. A linear variation of the irradiation induced dimensional change is assumed in this analysis.

Grade 2020 Graphite Emissivity

The emissivity of the grade 2020 graphite is assumed to be 0.9 . 


\section{Thermal Expansion of Inconel 718}

The thermal expansion of Inconel 718 (Ref. 7) is $14.2 \mathrm{E}-06 \mathrm{~K}^{-1}$

\section{THERMAL ANALYSIS MODEL}

Steady-state thermal analysis of the capsule was performed using computer code HEATING 7.2. This computer code (Ref. 8) is a multidimensional, general purpose heat transfer code. HEATING solves steady-state and/or transient problems in one, two or three dimensions. Because of the rotational symmetry of the capsule, the problem was solved using $\mathrm{R}, \mathrm{Z}$ geometry.

The model of the capsule follows the geometry shown in Figures 1 and 2. In addition, the ends of the capsule are also included in the model. Individual fuel compacts are modeled as separate regions, with associated power generation rates. Time dependent fission power in the fuel compacts was computed using CACA2 computer code for the initial fuel loading. Appropriate gamma heating (Ref. 3) is included in all regions, i.e., fuel compacts, the graphite fuel body, and the inconel pressure vessel. The thermocouples were not modeled in this initial analysis. Addition of the thermocouples in the thermal model increases the complexity of the analysis.

The thermal analysis for the beginning of life (beginning of cycle 1) is based on the initial fabricated dimensions of the compact, graphite fuel body and the inconel pressure vessel. As irradiation proceeds, the fuel compacts and the graphite fuel body change dimensions due to fast neutron induced effects. Both fuel compacts and the graphite fuel body shrink due to fast neutron damage. The shrinkage of the compacts and the graphite body changes the gaps. Change in the gap dimensions changes the conductance of the gaps, which in turn changes the operating temperature of the compacts. Therefore, irradiation induced dimensional changes must be included in the thermal analysis for all time points other than the beginning of life.

The changes in dimensions are computed using the correlations given above. The results of the dimensional changes analysis are shown in Table 1 . This table provides the predicted dimensions at the beginning and end of all four irradiation cycles. This analysis shows that the dimensional changes during the irradiation do not lead to interferences. Both cold gaps and hot gaps between the compact and the 
graphite fuel body increase with irradiation. Similarly, the gap between the graphite fuel body and the primary pressure vessel increases throughout the irradiation.

The evolution of the gap between the fuel compacts and the graphite fuel body is plotted in Figure 9. The cold gap increases from the initial value of 2.0 mils to $\sim 6.5$ mils at the end of irradiation at all compact positions. Similarly, the evolution of the cold gap between the graphite fuel body and the inconel primary pressure vessel is shown in Figure 10. This change is linear, since the 2020 graphite dimensional change is a linear function of fast fluence.

The original design of the capsule included a very low density, low thermal conductivity graphitic material plug supporting the fuel compact stack and the graphite fuel body. This plug shields the primary pressure vessel bottom end cap from the high temperature fuel compact. Concerns about possible shrinkage of the plug material (CARBOND) and subsequent possible relocation of the fuel in the capsule resulted in the redesign of the bottom of the capsule. This redesign includes a graphite ring attached to the bottom of the graphite fuel body to position the fuel compacts. The new design also includes a graphite disk as shown in the Heating 7 models shown in Figures 12, 13 and 14. Four small diameter graphite posts will be inserted into the CARBOND insulator plug to provide additional support to the graphite fuel body. These plugs were not included in the thermal model.

The thermal analysis is iterative in nature. An initial set of dimensions are used in the model and the thermal analysis is conducted for the start and end of irradiation. Helium/neon mixture is adjusted to obtain the desired compact average and maximum operating temperatures. Based on the initial results, adjustments are made to the initial dimensions and purge gas gaps and the analysis is repeated until satisfactory temperature profiles both at the start and end of irradiation are obtained. The analysis is then repeated for all the rest of time points to predict a time history of the compact operating temperatures.

This iterative thermal analysis showed that initial gap between the graphite fuel body and inconel pressure vessel at location of the middle compacts must be very small. The final gap chosen is 3.3 mils. This gap was used successfully in the earlier irradiation capsule HRB-21. 


\section{RESULTS OF THE THERMAL ANALYSIS}

The results or predictions of the operating temperatures in the fuel compacts at the beginning and end of each cycle are shown in Figures 11 through 29. These figures include the following:

a) an axial distribution of the maximum fuel compact temperature (the inner surface of the annular compact),

b) an axial distribution of the minimum fuel compact temperature (the outer surface of the compact),

c) volume average temperature of each compact,

d) the corresponding temperature at the location of the thermocouples for each compact, and

e) a radial temperature distribution along the midplane of each fuel compact.

Please note that the axial positions of the thermocouples do not correspond to the exact axial midplane of each compact, because the thermocouple design was for the original fuel compacts which were $40 \mathrm{~mm}$ long as compared to the replacement compacts which are $39 \mathrm{~mm}$ long.

Although the thermocouples were not explicitly modeled in this analysis the temperature of the node at the location of the thermocouple is shown in these plots. The actual measured temperature at these locations may be slightly different due to enhanced gamma heat generation in the thermocouple materials.

The difference in the power production in each compact is the greatest at the beginning of each cycle. For example at the beginning of cycle 1 compact 1 power is $49 \mathrm{~W} / \mathrm{cc}$ as compared to $128 \mathrm{~W} / \mathrm{cc}$ for compact 6. The axial temperature distribution shows this power variation. At the end of the cycle the power production in the compacts away from the axial midplane increase and the axial temperature distribution flattens out as seen in these figures.

The fuel compact operating conditions are within the requirements at all time points except at the beginning of cycle 4 . Here the calculated maximum fuel temperature is about $50 \mathrm{C}$ higher than the allowable value of $1350 \mathrm{C}$. Since the initial gap between the graphite fuel body and the inconel pressure vessel cannot be further reduced, another method must be devised to achieve the same goal. If the reactor operating power at the start of the fourth cycle can be lowered for a few days, the compact maximum temperatures may be kept below the maximum permissible value. To achieve this additional analysis was 
performed. Acceptable fuel operating temperatures were obtained by reducing the reactor power to 78 $M W(t)$ for the first four days of cycle 4. The results shown in Figures 26 and 27 represent the lower power operation of the HFIR (78 MWt) at the start of cycle 4. This low power operation shall last for 4 days, at which time the reactor power can be raised to its normal operation conditions of $85 \mathrm{MWt}$.

Finally, a typical temperature profile. through the compact, graphite fuel body and the pressure vessels is shown in three dimensional representation in Figure 30. Here the two pressure vessels are seen first, followed by the graphite body and finally the fuel compacts.

One of the safety concerns relates to possible local contact between the primary and secondary pressure vessels. This local contact will alter the temperature fields at that location. The concern is that the local contact may increase the temperature of the primary pressure vessel beyond design allowable value. To understand this problem, a new thermal model in HEATING was formulated. Instead of analyzing the eccentricity of the pressure vessels, the gap between the two containments was filled by an Inconel region approximately $1 \mathrm{~mm}$ wide and running the entire length of the fuel stack. This models a small contact region representing a line contact between the pressure vessels. The condition at the end of cycle 2 was chosen for the analysis. The results are compared to the case of no contact in Figure 31 . The contact eliminates the temperature drop across the gap between the pressure vessels and decreases the temperature of the inner surface of the primary containment. This is easily understood, since the thermal conductivity of inconel is greater than the thermal conductivity of helium in the gap. There are no safety concerns with local contact between the pressure vessels.

Finally temperature distributions of the inside surfaces of the inconel primary and secondary pressure vessels are shown in Figure 32. Maximum value of the surface temperature any time during the four cycles of test operation is shown along the axial direction of the capsule. The maximum predicted temperature of the primary vessel is near $350 \mathrm{C}$ at the axial midpoint. The secondary vessel maximum temperature is about $210 \mathrm{C}$. 


\section{REFERENCES:}

1. Allen, E.J., CACA-2: Revised Version of CACA - A Heavy Isotope and Fission Product Concentration Calculational Code for Experimental Irradiation Capsules, ORNL/TM-5266, Union Carbide Corporation Nuclear Div., Oak Ridge national Laboratory, February 1976.

2. Memo, J.T. Parks to K. R. Thoms, "Transmittal of QA Package for the New HRB-22 Replacement Fuel compacts," February 24, 1993.

3. R. L. Senn and W. R. Mixon, "Experimental Measurement of Gamma Heat in the High Flux Isotope Reactor," Nucl. Technol. 12, 235 (1971).

4. Kousaku Fukuda, et al., "Research and Development of HTGR Fuels, " JAERI-M 89-007, January 13, 1989.

5. Graphite Design Data Manual, GA Document No. 906374, Issue A, August 1984.

6. HTK \& Post Irradiation Data

7. Huntington Alloys Handbook

8. K.W. Childs, "HEATING 7.2 User's Manual," ORNL-TM-12262, Computer Applications Division, Oak Ridge National Laboratory, February 1993. 


\begin{tabular}{|c|c|c|c|c|c|c|c|c|c|c|c|c|c|c|c|}
\hline \multirow{3}{*}{$\begin{array}{l}\text { Table 1. } \\
\text { Database } \\
\end{array}$} & \multicolumn{5}{|c|}{$\begin{array}{l}\text { redicted Dimensional Changes of Fuel Compacts and Graphite F } \\
\text { Thermal expansion of SP2020 (Graphite Design data Manual) }\end{array}$} & & & & $3.20 \mathrm{e}-6 / \mathrm{C}$ & & & & & & \\
\hline & \multicolumn{5}{|c|}{ Thermal expansion of Inconel-718 (Huntington Alloys) } & & & & $14.2 \mathrm{e}-6 / \mathrm{C}$ & & & & & & \\
\hline & \multicolumn{3}{|c|}{ Thermal expansion of Fuel Compacts } & & & & & & $2.45 \mathrm{e}-6 / \mathrm{C}$ & & & & & & \\
\hline & \multicolumn{4}{|c|}{ Initial radial gap between fuel and graphite $f_{g}$} & & & & & $2.0 \mathrm{mils}$ & & & & & & \\
\hline & \multicolumn{3}{|c|}{ Average fuel temperature (C) } & & & & & & 1200 & & & & & & \\
\hline & \multicolumn{3}{|c|}{ Average graphite temperature (C) } & & & & & & 800 & & & & & & \\
\hline & \multirow{2}{*}{\multicolumn{5}{|c|}{\begin{tabular}{|l|l|} 
Inconel inside surface temperature (C) & \\
Fuel dimensional change (Fluence Dependance) & $-\ldots \ldots . . .>$ \\
\end{tabular}}} & & & & 300 & & & & & & \\
\hline & & & & & & & & & \multicolumn{4}{|c|}{ deltaD/D=1.74e-3*fluence $2-1.006 \mathrm{e}-2^{\wedge}$ fluence } & & & \\
\hline & \multicolumn{5}{|c|}{ Unirradiated Fuel Thermal Conductivity ..............> } & & & & \multicolumn{5}{|c|}{ Kunirr $=1.014 \mathrm{e}-7^{\star} \mathrm{T}^{\wedge} 2-2.919 \mathrm{e}-4^{*} \mathrm{~T}+0.3896(\mathrm{~W} / \mathrm{cm} . \mathrm{K})$} & & \\
\hline & \multicolumn{5}{|c|}{ Fluence dependence } & & & & \multicolumn{5}{|c|}{ Kirrad $=$ Kunirr* $^{*}\left(5.314 \mathrm{e} 2^{*}\right.$ flux $2-0.2931^{*}$ flux +1$)$} & & \\
\hline & \multicolumn{5}{|c|}{ Assumed shrinkage of SP2020 graphite is - } & & & & \multicolumn{3}{|c|}{$1.1 \%$ (linear) at a fluence of $5 \mathrm{e} 25 \mathrm{n} / \mathrm{m} 2$} & & & & \\
\hline & & & & & & & & & & & & & & & \\
\hline & & & & & & & & \multirow{2}{*}{\multicolumn{4}{|c|}{$\langle-\cdots-$ Graphite Outside Dia/radius -..._- }} & & & & \\
\hline & cold & \multicolumn{2}{|c|}{$\ldots$} & \multicolumn{3}{|c|}{$<--$ Graphite Inside Radius -.. } & $\frac{\text { f g gap }}{\text { hot }}$ & & & & & Cold & Hot & $<\ldots$ & $\frac{\text { g.nc }}{\text { Radial gap }}$ \\
\hline & $\mathrm{cm}$ & $\frac{\mathrm{cm}}{\mathrm{chrad}}$ & $\frac{\text { hot }}{\mathrm{cm}}$ & $\mathrm{cm}$ & $\mathrm{cm}$ & $\mathrm{cm}$ & mils & Dia (in) & (in) & Dia (in) & $\mathrm{cm}$ & Dia (in) & Dia (in) & $\mathrm{cm}$ & hot mils \\
\hline \multicolumn{16}{|l|}{ BOC 1} \\
\hline Region 1 & 1.3025 & 1.30250 & 1.30551 & 1.30758 & 1.30758 & 1.31098 & 2.15 & 1.4750 & 1.47500 & 1.47884 & 1.87812 & 1.5115 & 1.5166 & 1.92614 & 18.9 \\
\hline Region 2 & 1.3025 & 1.30250 & 1.30576 & 1.30758 & 1.30758 & 1.31115 & 2.12 & 1.4920 & 1.49200 & 1.49607 & 1.90001 & 1.5115 & 1.5166 & 1.92614 & 10.3 \\
\hline Region 3 & 1.3025 & 1.30250 & 1.30599 & 1.30758 & 1.30758 & 1.31127 & 2.08 & 1.4920 & 1.49200 & 1.49622 & 1.90019 & 1.5115 & 1.5166 & 1.92614 & 10.2 \\
\hline Region 4 & 1.3025 & 1.30250 & 1.30580 & 1.30758 & 1.30758 & 1.31073 & 1.94 & 1.5050 & 1.50500 & 1.50863 & 1.91596 & 1.5115 & 1.5166 & 1.92614 & 4.0 \\
\hline Region 5 & 1.3025 & 1.30250 & 1.30592 & 1.30758 & 1.30758 & 1.31086 & 1.94 & 1.5050 & 1.50500 & 1.50877 & 1.91614 & 1.5115 & 1.5166 & 1.92614 & 3.9 \\
\hline Region 6 & 1.3025 & 1.30250 & 1.30605 & 1.30758 & 1.30758 & 1.31094 & 1.92 & 1.5050 & 1.50500 & 1.50887 & 1.91626 & 1.5115 & 1.5166 & 1.92614 & 3.9 \\
\hline EOC 1 & & & & & & & & & & & & & & & \\
\hline Region 1 & 1.3025 & 1.29773 & 1.30118 & 1.30758 & 1.30646 & 1.31011 & 3.52 & 1.4750 & 1.47373 & 1.47785 & 1.87687 & 1.5115 & 1.5171 & 1.92673 & 19.6 \\
\hline Region 2 & 1.3025 & 1.29662 & 1.30025 & 1.30758 & 1.30617 & 1.30982 & 3.77 & 1.4920 & 1.49039 & 1.49456 & 1.89809 & 1.5115 & 1.5171 & 1.92673 & 11.3 \\
\hline Region 3 & 1.3025 & 1.29566 & 1.29948 & 1.30758 & 1.30591 & 1.30964 & 4.00 & 1.4920 & 1.49010 & 1.49435 & 1.89783 & 1.5115 & 1.5171 & 1.92673 & 11.4 \\
\hline Region 4 & 1.3025 & 1.29484 & 1.29856 & 1.30758 & 1.30568 & 1.30891 & 4.08 & 1.5050 & 1.50281 & 1.50653 & 1.91330 & 1.5115 & 1.5171 & 1.92673 & 5.3 \\
\hline Region 5 & 1.3025 & 1.29414 & 1.29783 & 1.30758 & 1.30548 & 1.30867 & 4.27 & 1.5050 & 1.50258 & 1.50625 & 1.91294 & 1.5115 & 1.5171 & 1.92673 & 5.4 \\
\hline Region 6 & 1.3025 & 1.29356 & 1.29731 & 1.30758 & 1.30531 & 1.30854 & 4.42 & 1.5050 & 1.50238 & 1.50610 & 1.91275 & 1.5115 & 1.5171 & 1.92673 & 5.5 \\
\hline $\mathrm{BOC2}$ & & & & & & & & & & & & & & & \\
\hline Region I & 1.3025 & 1.29773 & 1.30048 & 1.30758 & 1.30646 & 1.30944 & 3.53 & 1.4750 & 1.47373 & 1.47710 & 1.87591 & 1.5115 & 1.5169 & 1.92641 & 19.9 \\
\hline Region 2 & 1.3025 & 1.29662 & 1.29968 & 1.30758 & 1.30617 & 1.30928 & 3.78 & 1.4920 & 1.49039 & 1.49394 & 1.89730 & 1.5115 & 1.5169 & 1.92641 & 11.5 \\
\hline Region 3 & 1.3025 & 1.29566 & 1.29907 & 1.30758 & 1.30591 & 1.30927 & 4.02 & 1.4920 & 1.49010 & 1.49393 & 1.89728 & 1.5115 & 1.5169 & 1.92641 & 11.5 \\
\hline Region 4 & 1.3025 & 1.29484 & 1.29827 & 1.30758 & 1.30568 & 1.30866 & 4.09 & 1.5050 & 1.50281 & 1.50624 & 1.91293 & 1.5115 & 1.5169 & 1.92641 & 5.3 \\
\hline Region 5 & 1.3025 & 1.29414 & 1.29783 & 1.30758 & 1.30548 & 1.30863 & 4.25 & 1.5050 & 1.50258 & 1.50620 & 1.91288 & 1.5115 & 1.5169 & 1.92641 & 5.3 \\
\hline Region 6 & 1.3025 & 1.29356 & 1.29738 & 1.30758 & 1.30531 & 1.30854 & 4.39 & 1.5050 & 1.50238 & 1.50610 & 1.91275 & 1.5115 & 1.5169 & 1.92641 & 5.4 \\
\hline EOC 2 & & & & & & & & & & & & & & & \\
\hline Region 1 & 1.3025 & 1.29356 & 1.29709 & 1.30758 & 1.30531 & 1.30895 & 4.67 & 1.4750 & 1.47244 & 1.47655 & 1.87522 & 1.5115 & 1.5168 & 1.92632 & 20.1 \\
\hline Region 2 & 1.3025 & 1.29184 & 1.29555 & 1.30758 & 1.30476 & 1.30832 & 5.03 & 1.4920 & 1.48878 & 1.49285 & 1.89592 & 1.5115 & 1.5168 & 1.92632 & 12.0 \\
\hline Region 3 & 1.3025 & 1.29027 & 1.29411 & 1.30758 & 1.30421 & 1.30786 & 5.41 & 1.4920 & 1.48816 & 1.49232 & 1.89524 & 1.5115 & 1.5168 & 1.92632 & 12.2 \\
\hline Region 4 & 1.3025 & 1.28908 & 1.29285 & 1.30758 & 1.30375 & 1.30698 & 5.56 & 1.5050 & 1.50060 & 1.50431 & 1.91047 & 1.5115 & 1.5168 & 1.92632 & 6.2 \\
\hline Region 5 & 1.3025 & 1.28820 & 1.29193 & 1.30758 & $1 . \overline{30338}$ & 1.30652 & 5.74 & 1.5050 & 1.50017 & 1.50378 & 1.90980 & 1.5115 & 1.5168 & 1.92632 & 6.5 \\
\hline Region 6 & 1.3025 & 1.28751 & 1.29131 & 1.30758 & 1.30306 & 1.30625 & 5.88 & 1.5050 & 1.49980 & 1.50346 & 1.90940 & 1.5115 & 1.5168 & 1.92632 & 6.7 \\
\hline
\end{tabular}




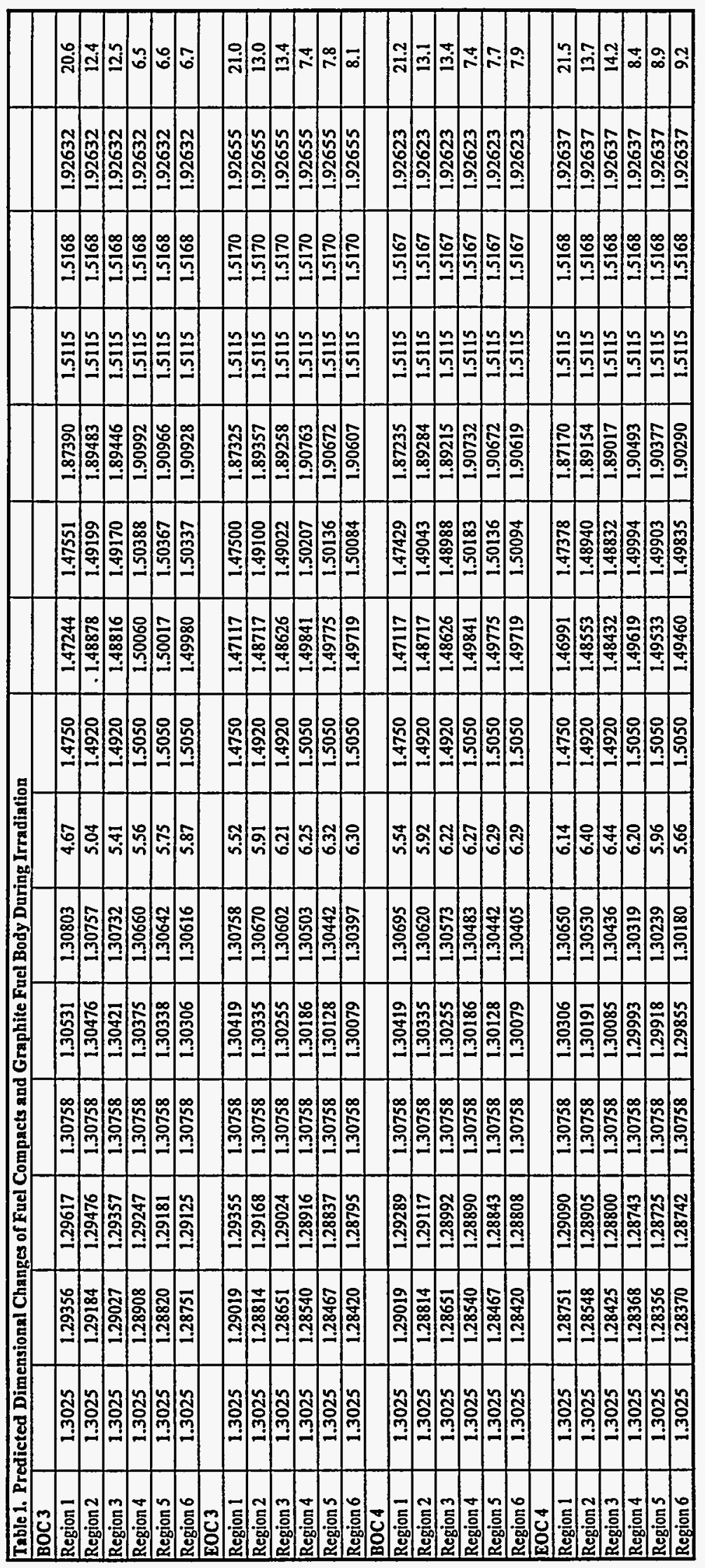




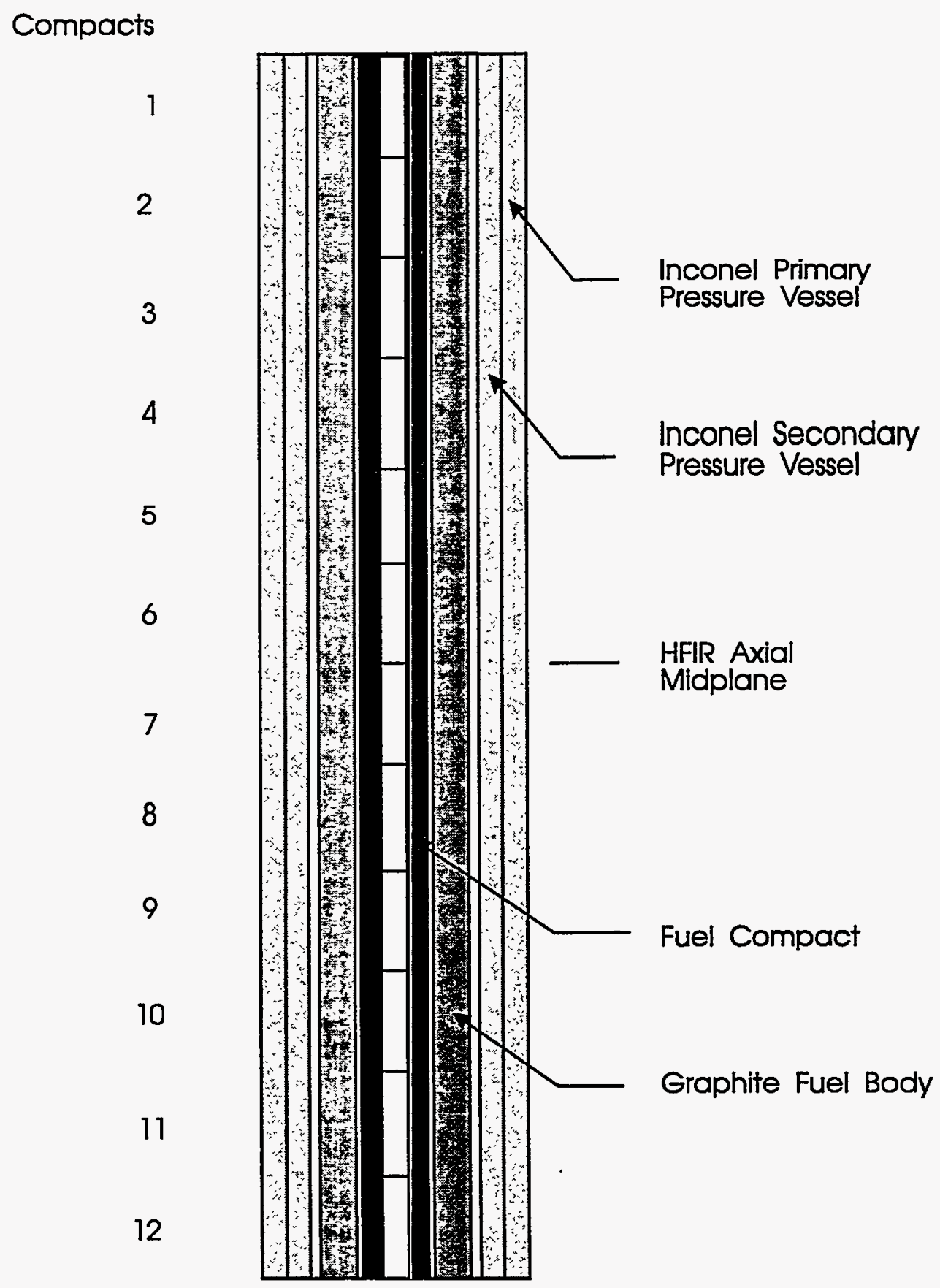

Figure 1. Axial Cross Section of HRB-22 Irradiation Capsule 


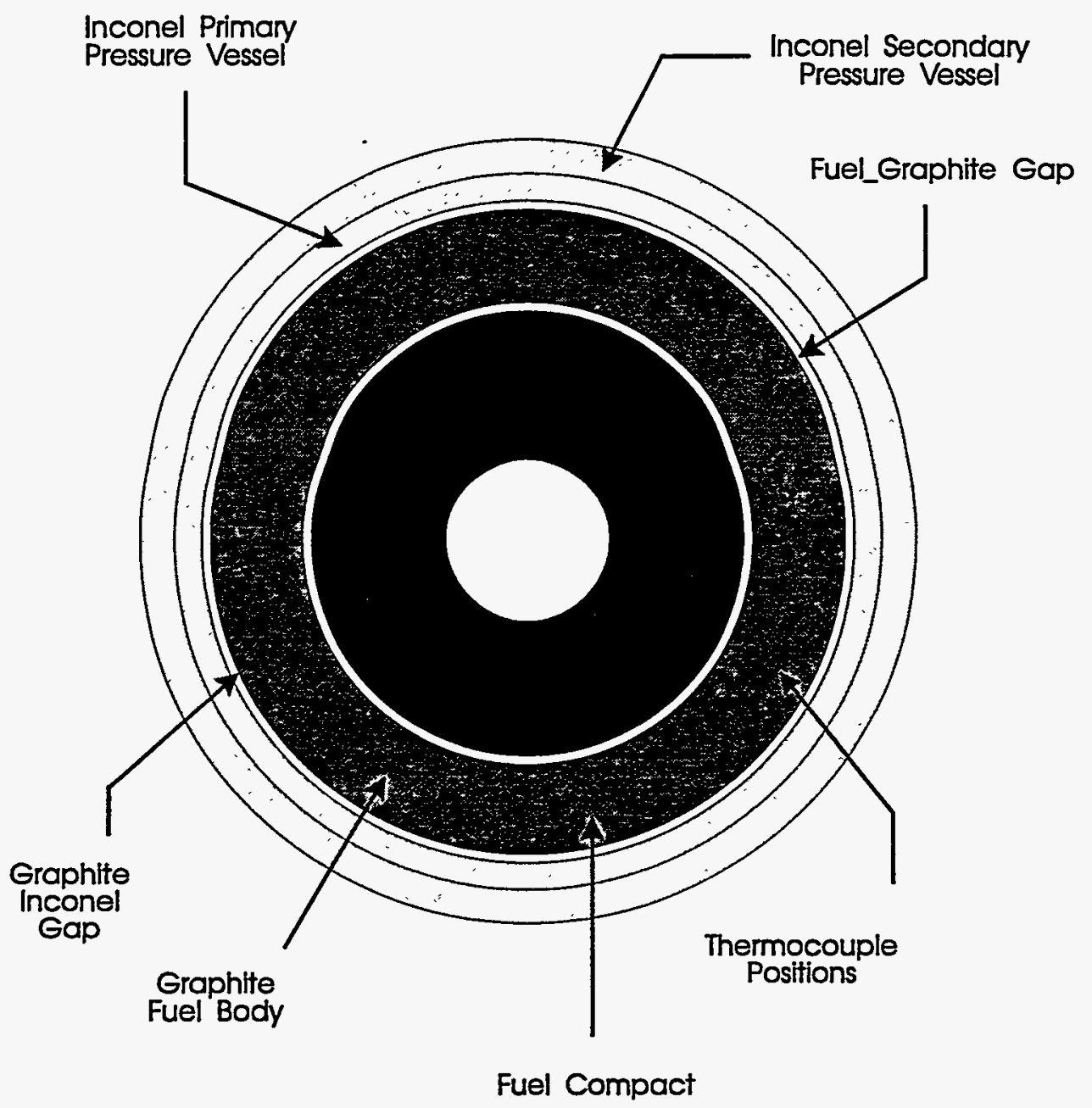

Figure 2. Radial Cross Section of HRB-22 Irradiation Capsule 


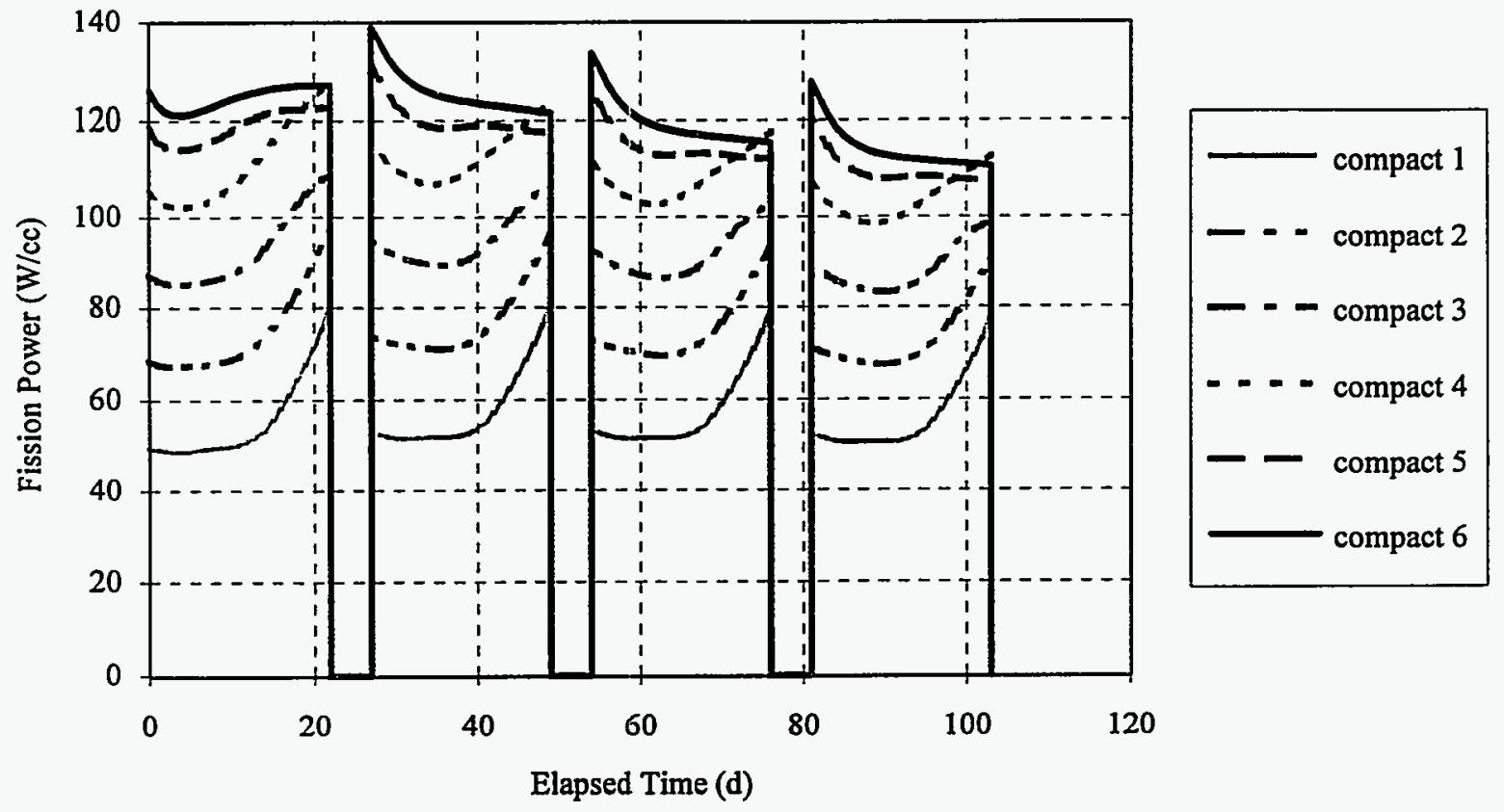

Figure 3. Predicted Total Power History for Individual Compacts

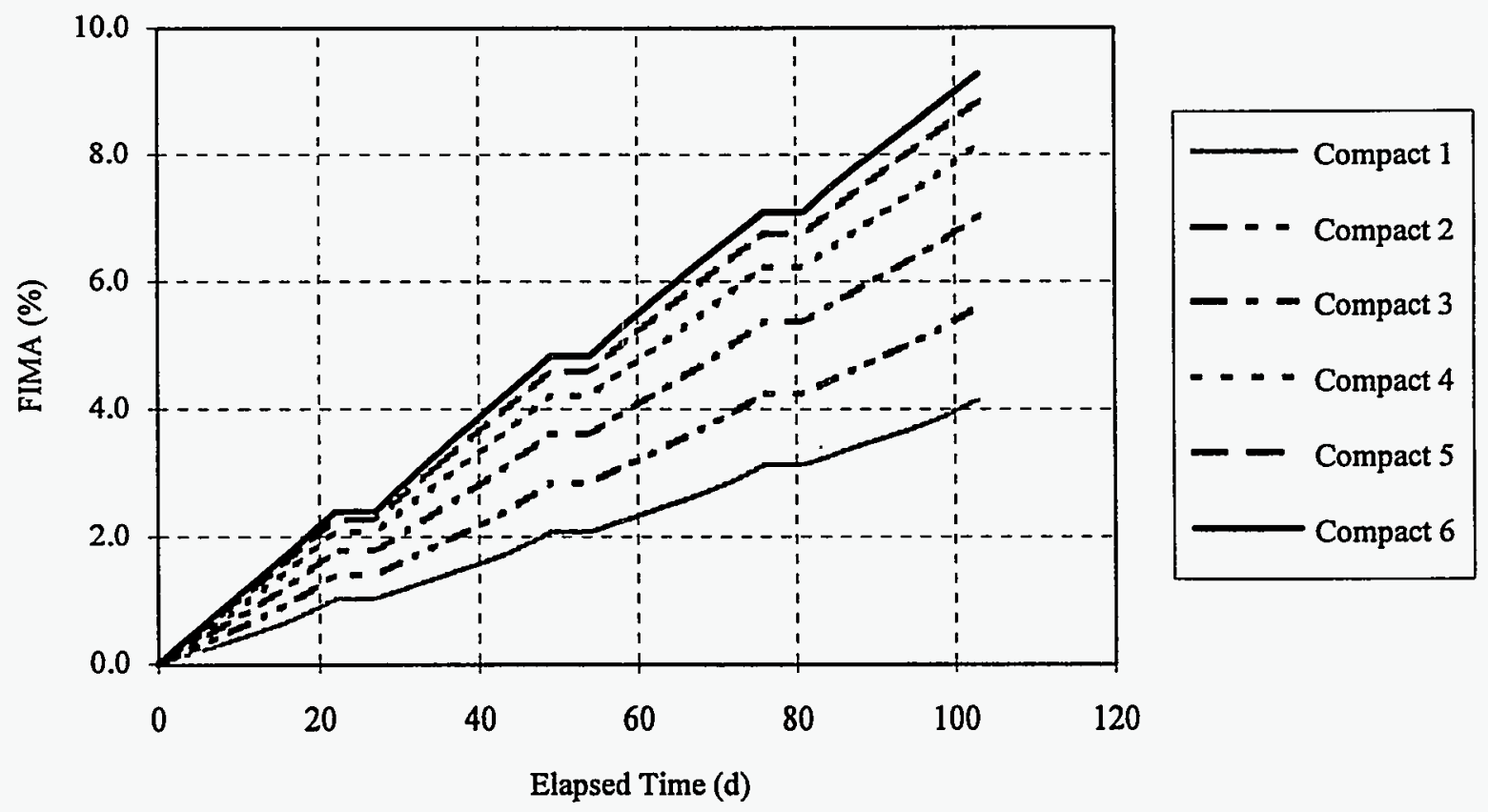

Figure 4. Predicted Burnup for Individual Compacts 


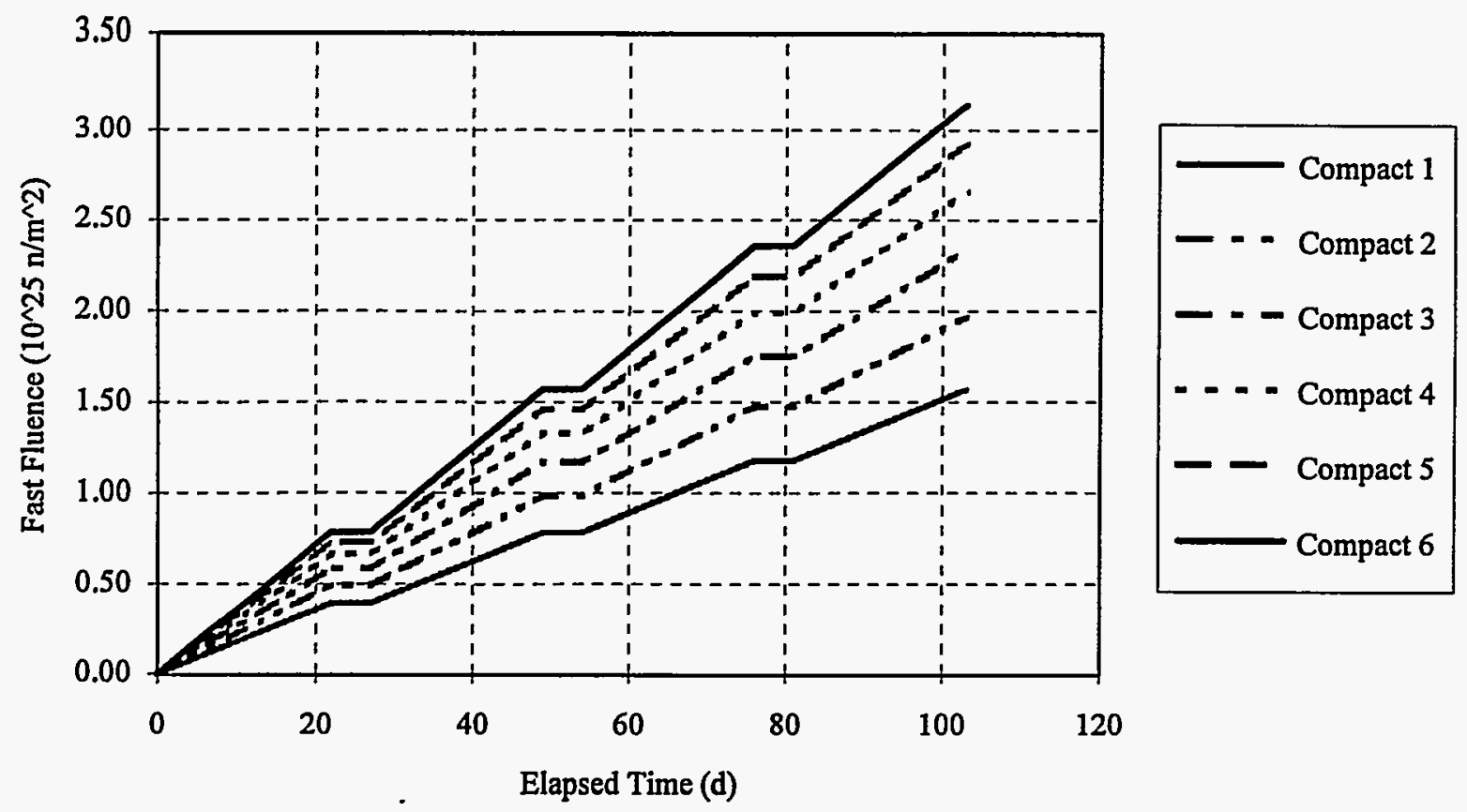

Figure 5. Predicted Fast Fluence for Individual Compacts

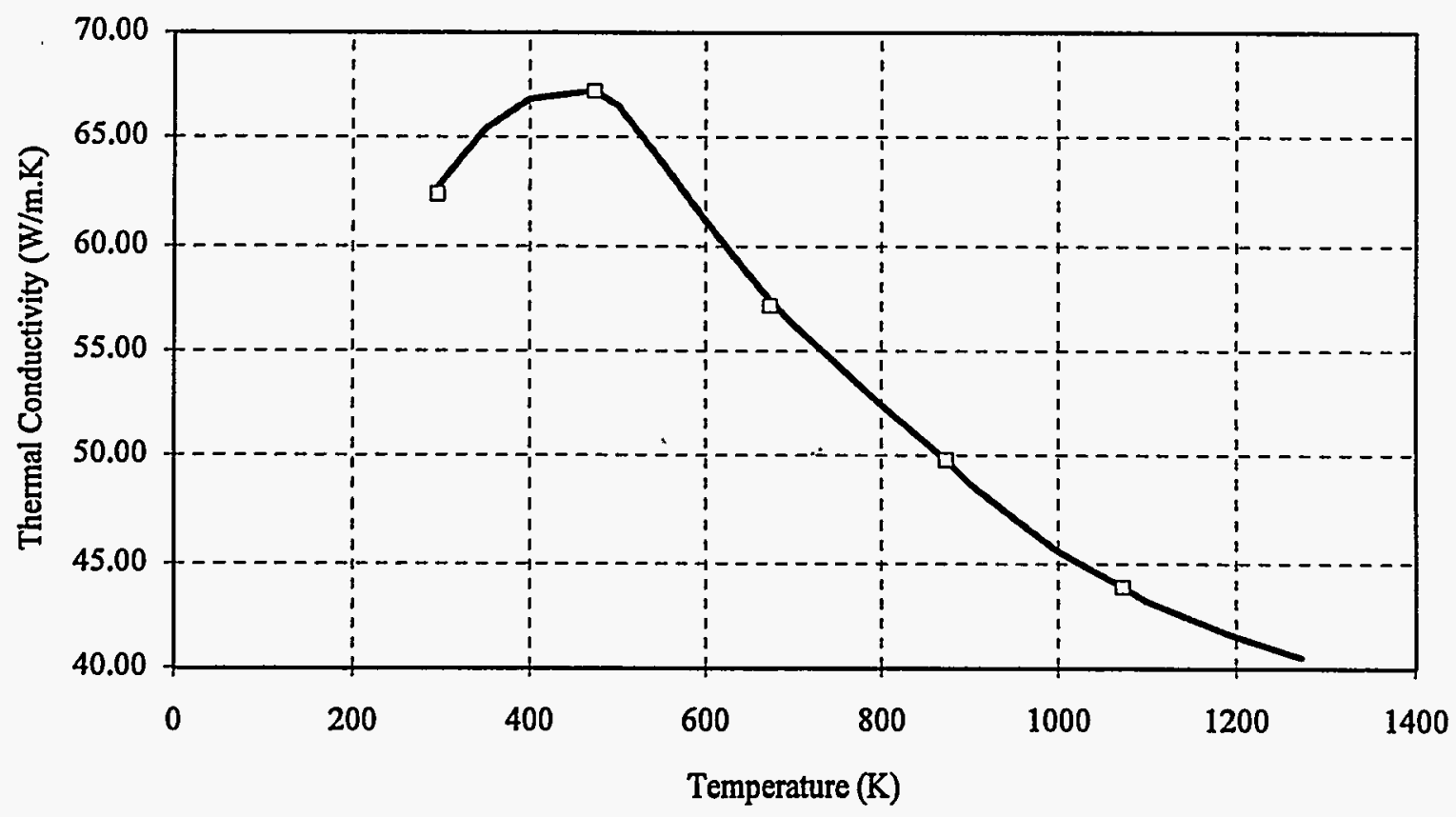

Figure 6. Thermal Conductivity of Unirradiated Grade 2020 Graphite 


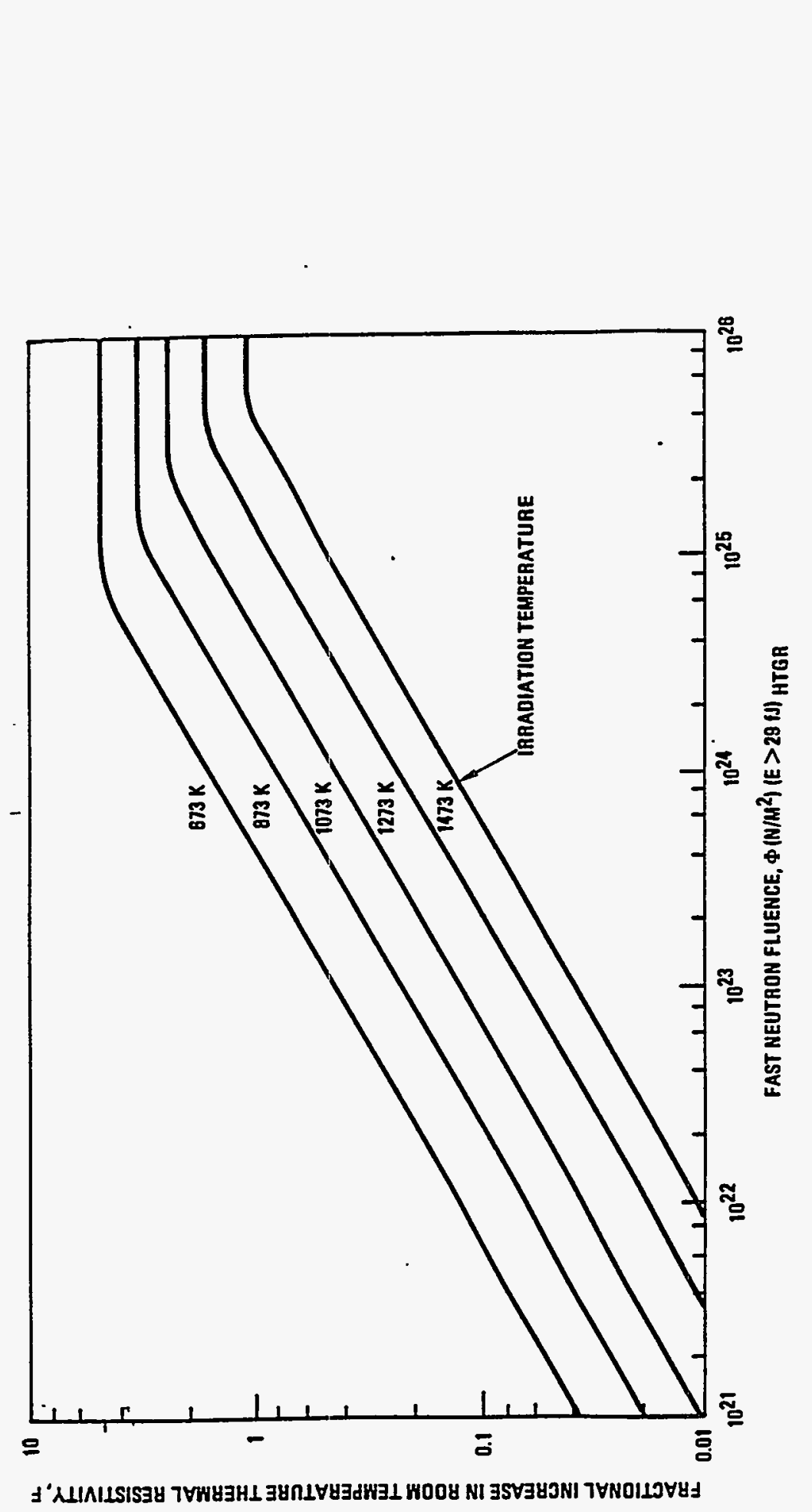




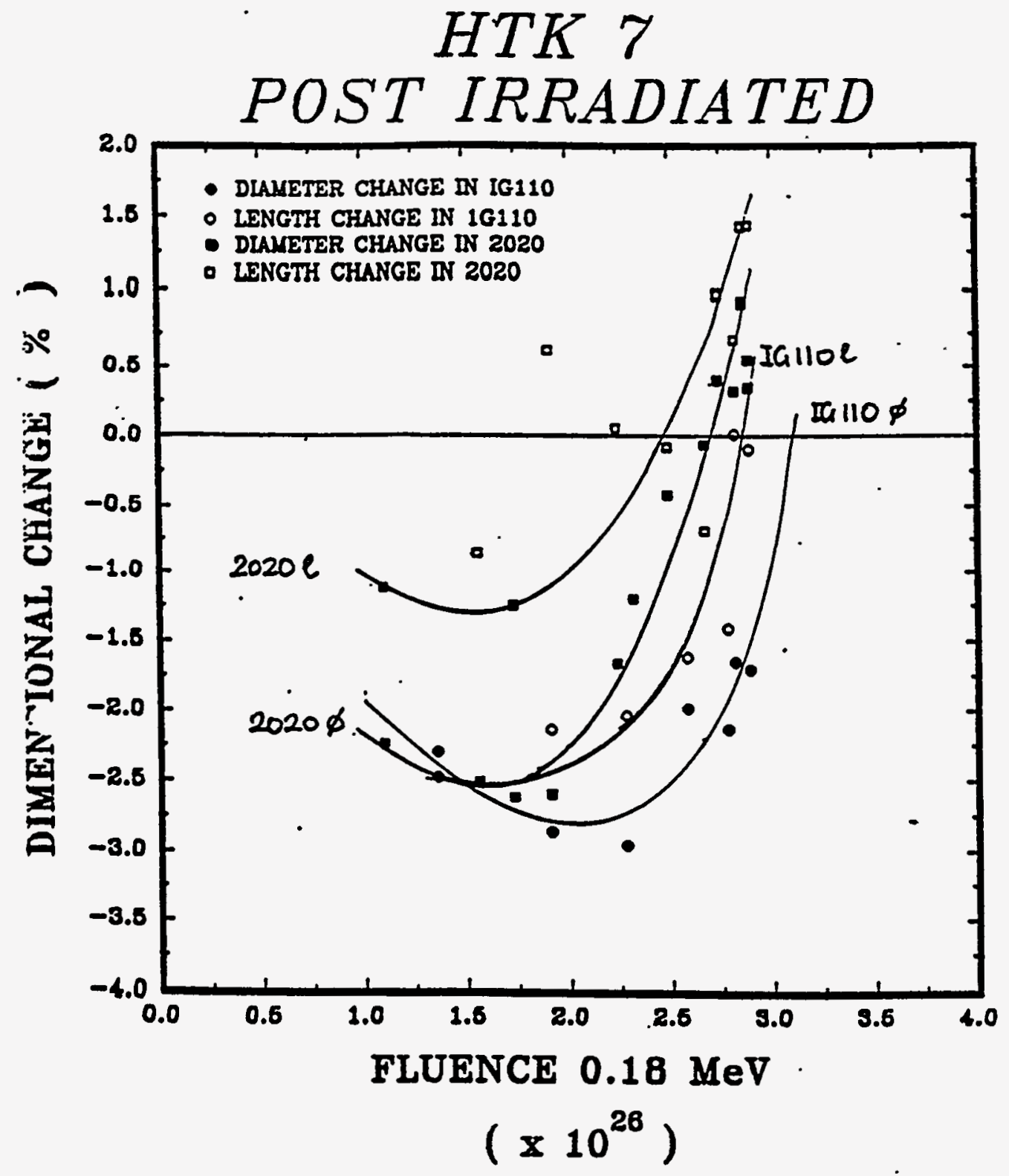

Figure 8. Dimensional change of grade 2020 graphite as function of fast fluence 


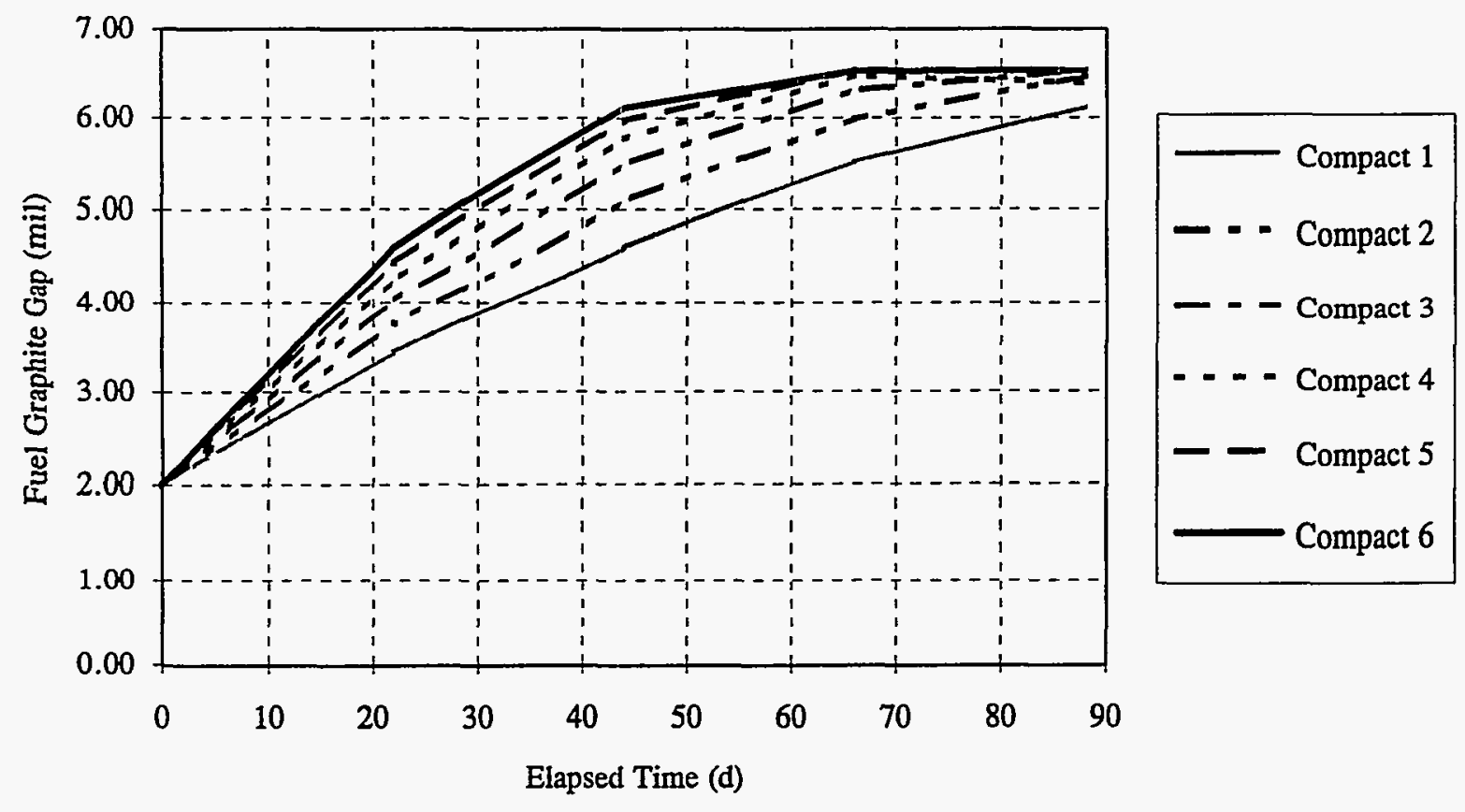

Figure 9. Evolution of The Cold Gap Between The Fuel Compact and Graphite Fuel Body

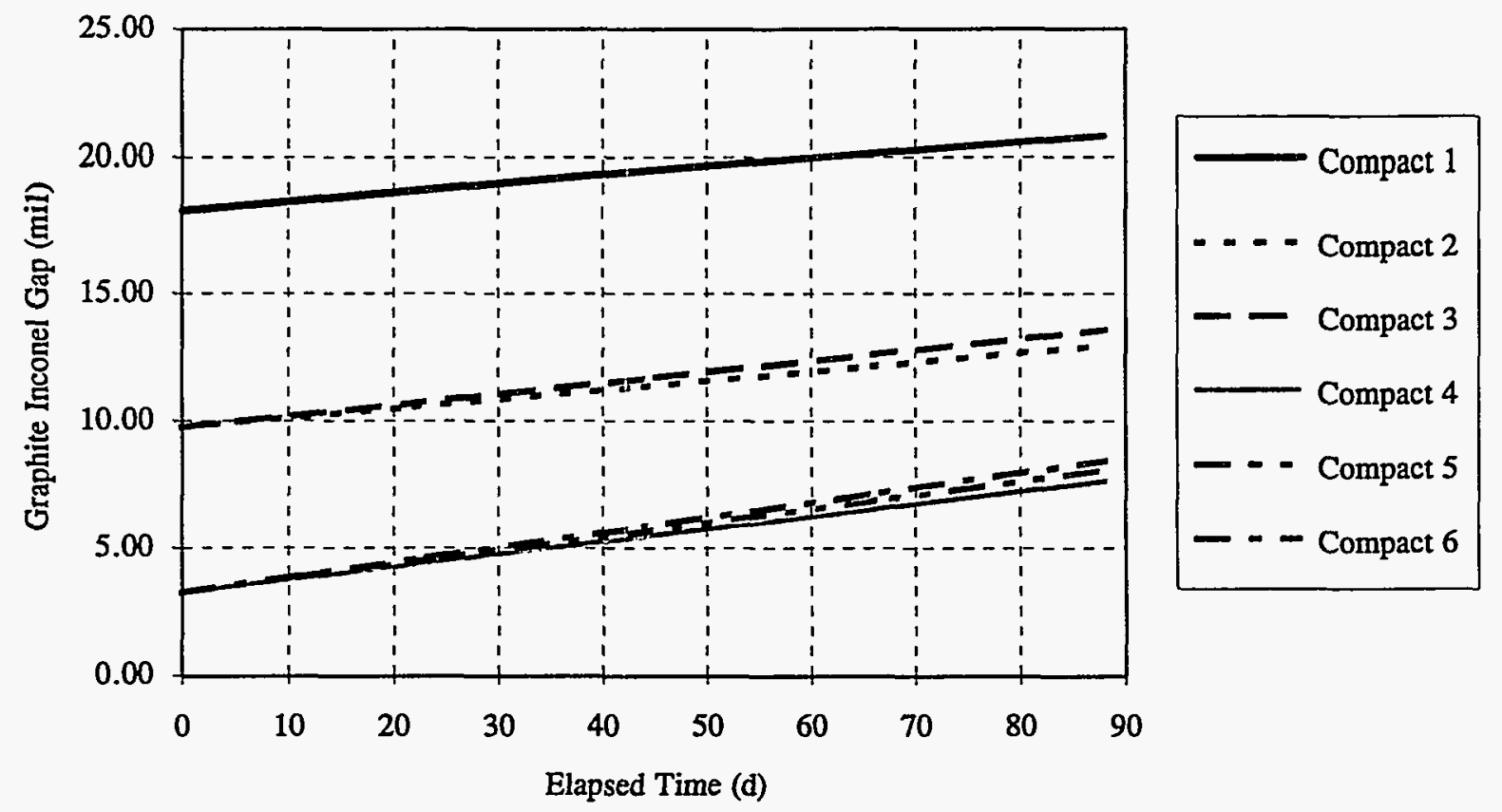

Figure 10. Evolution of The Cold Gap between The Graphite Fuel Body and Primary Inconel Pressure vessel 


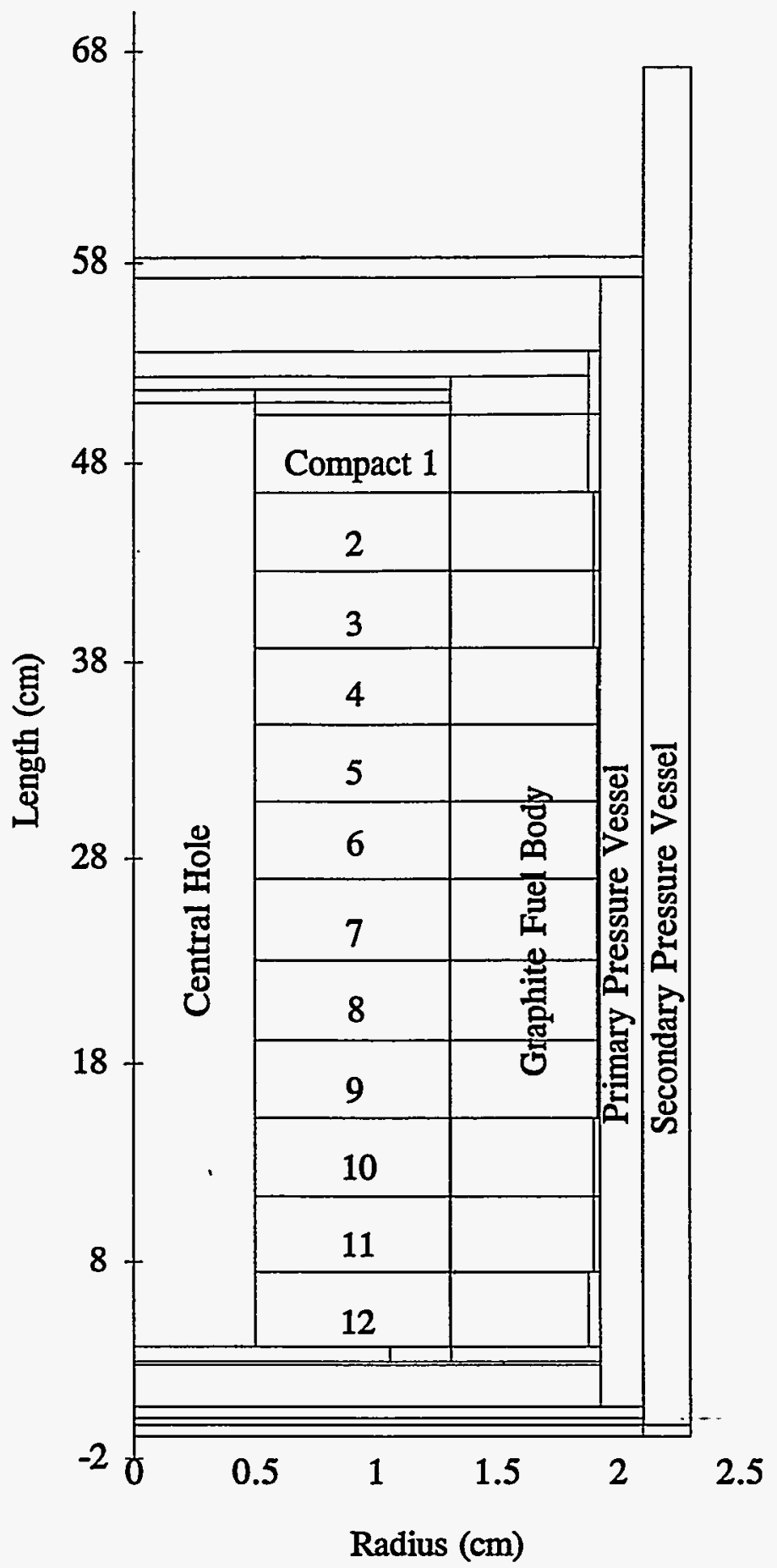

Figure 11. HEATING 7 Model of Capsule HRB-22 


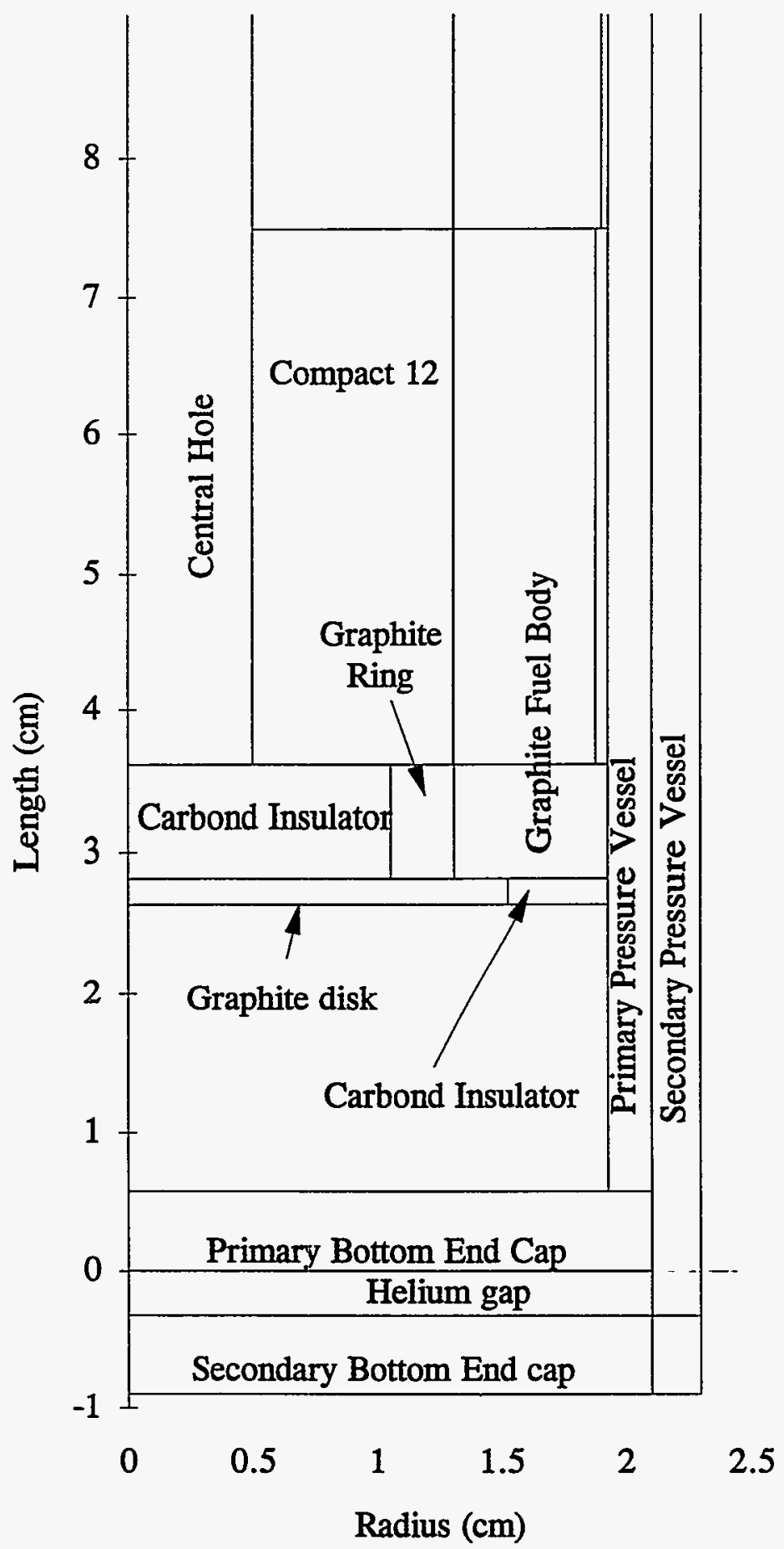

Figure 12. HEATING 7 Model, Bottom of capsule details 


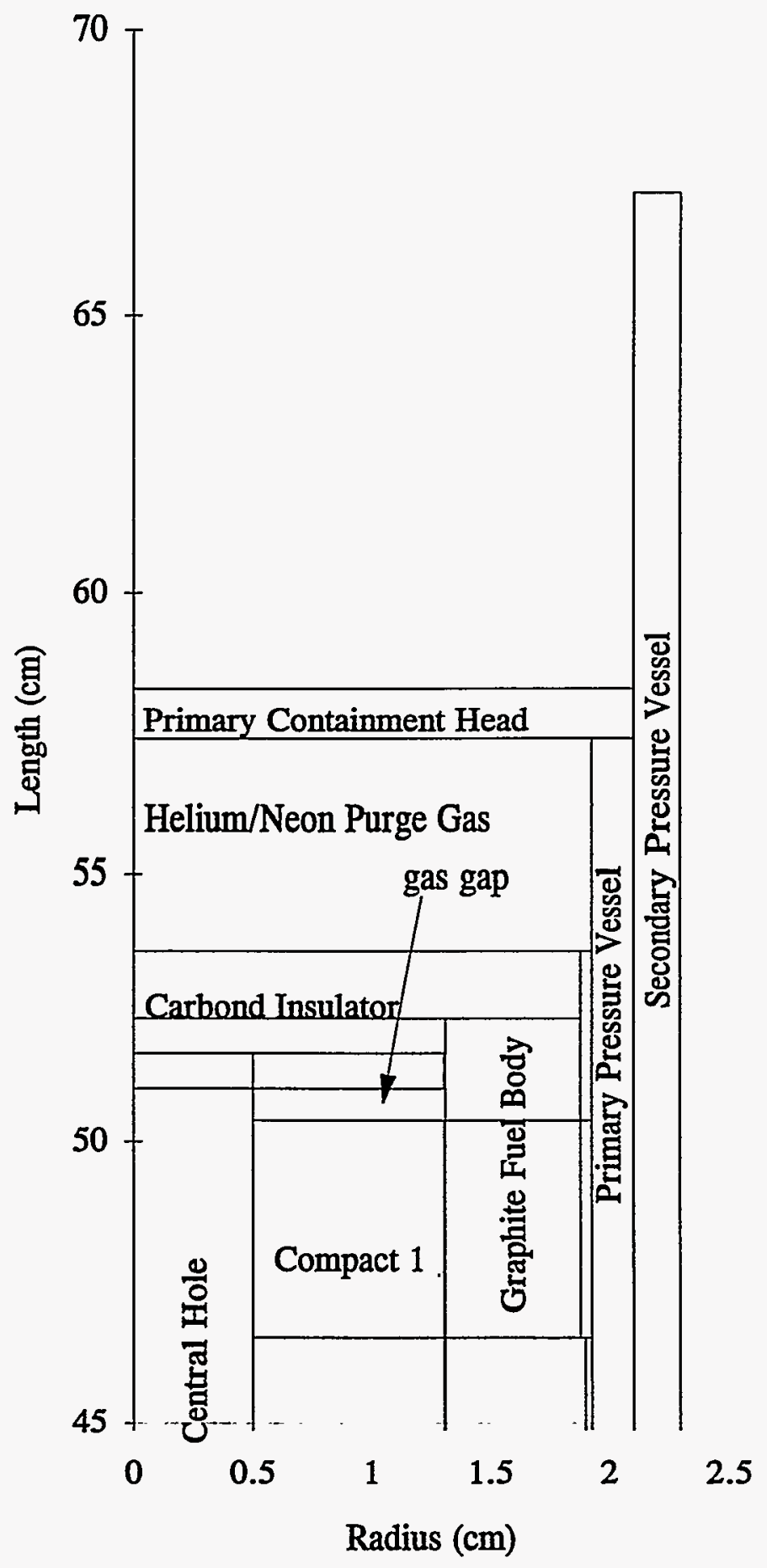

Figure 13. HEATING 7 Model Top of Capsule Details 


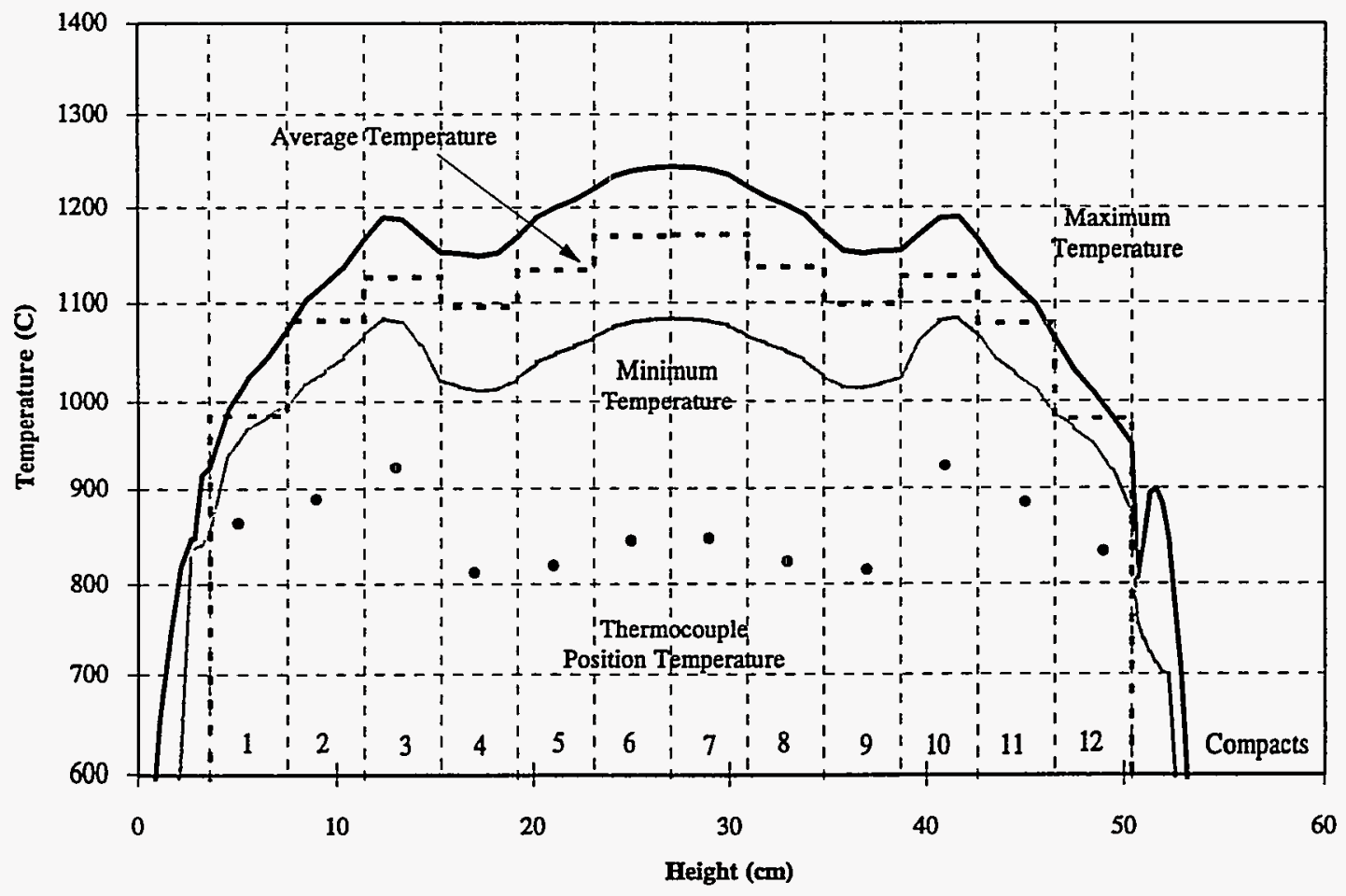

Figure 14. Beginning of Cycle 1 Axial temperature Distribution

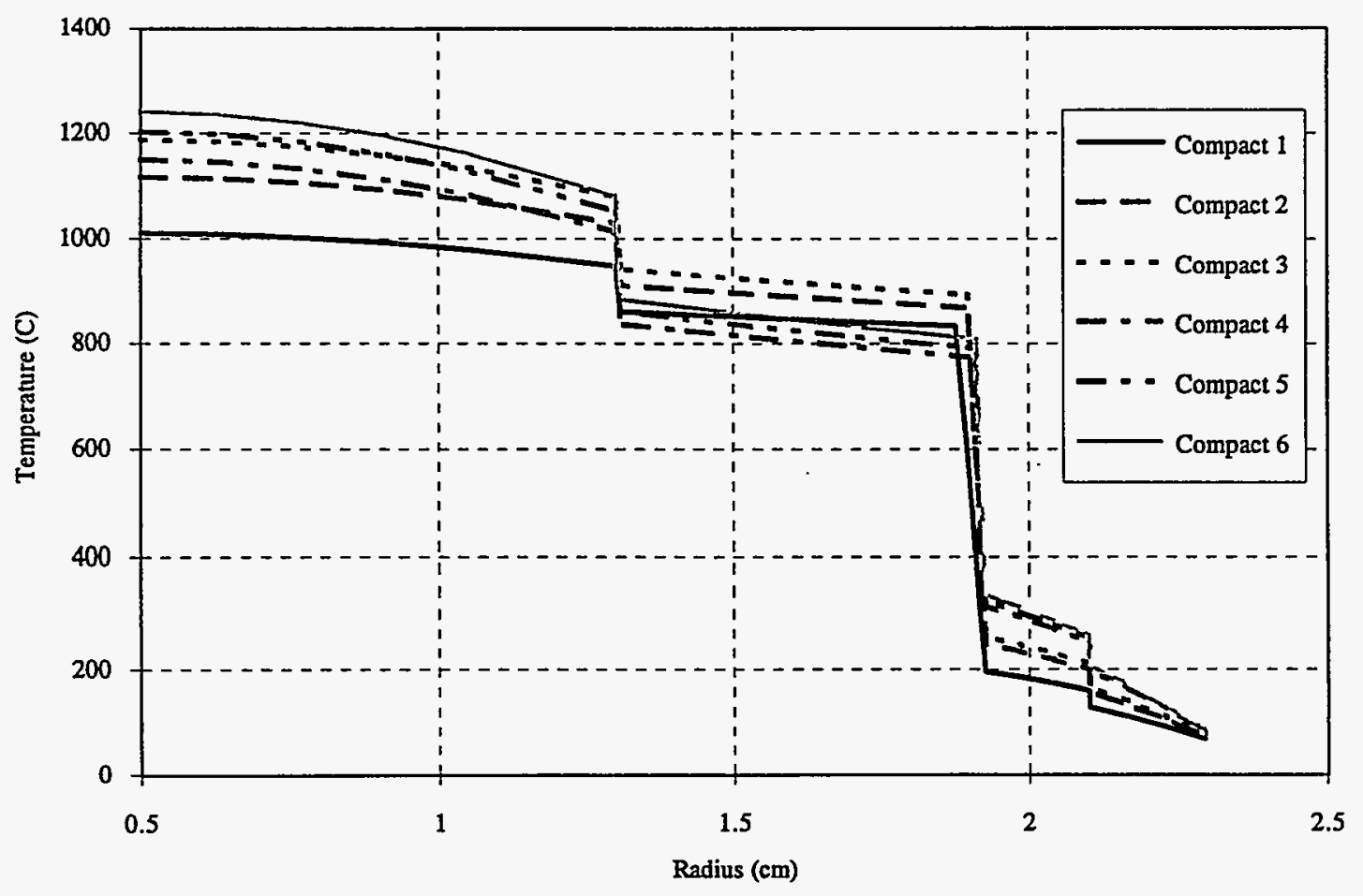

Figure 15. Beginning of Cycle Radial Temperature Distribution 


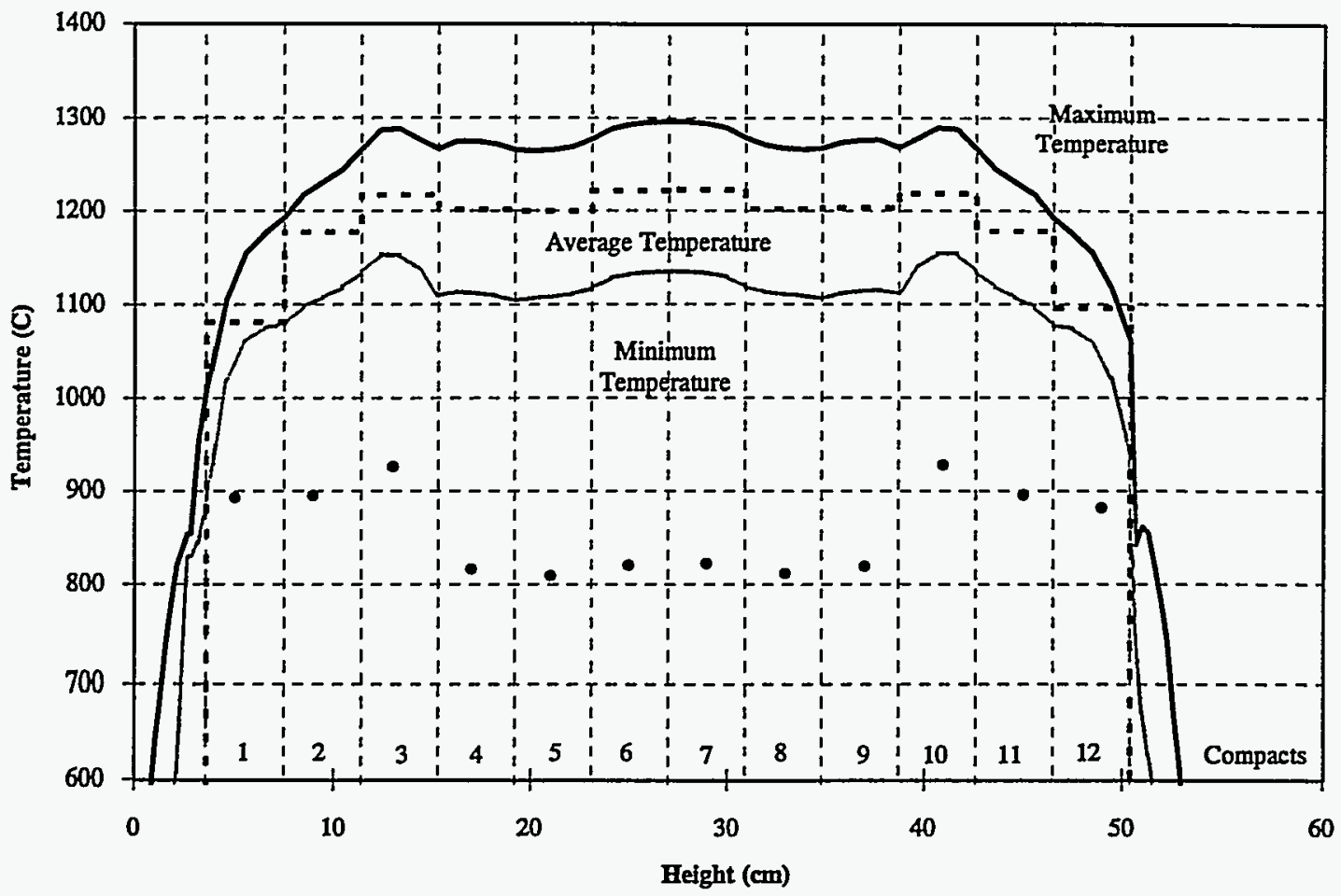

Figure 16. End of Cycle 1 Axial Temperature Distribution

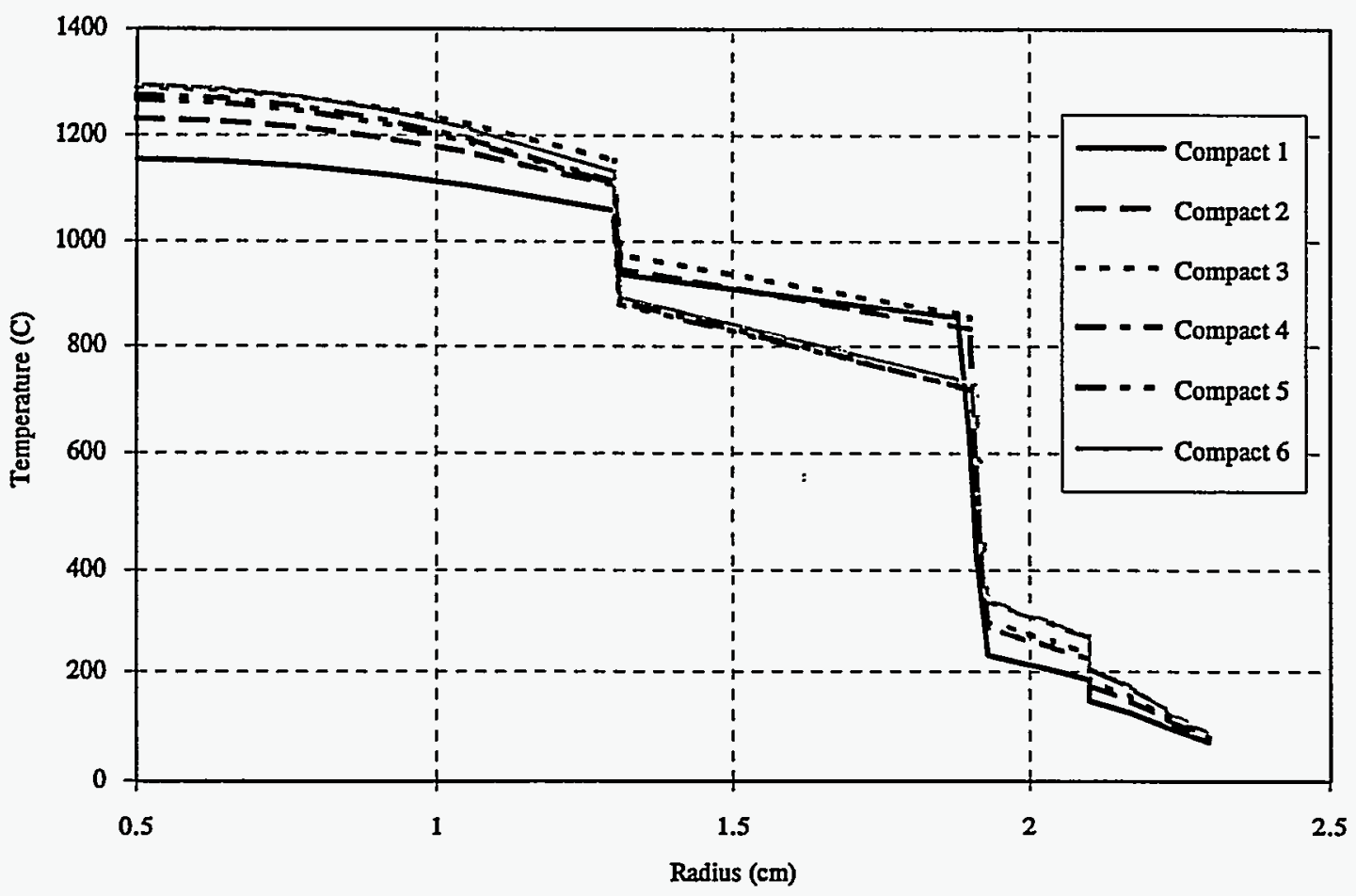

Figure 17. End of Cycle 1 Radial Temperature Distribution 


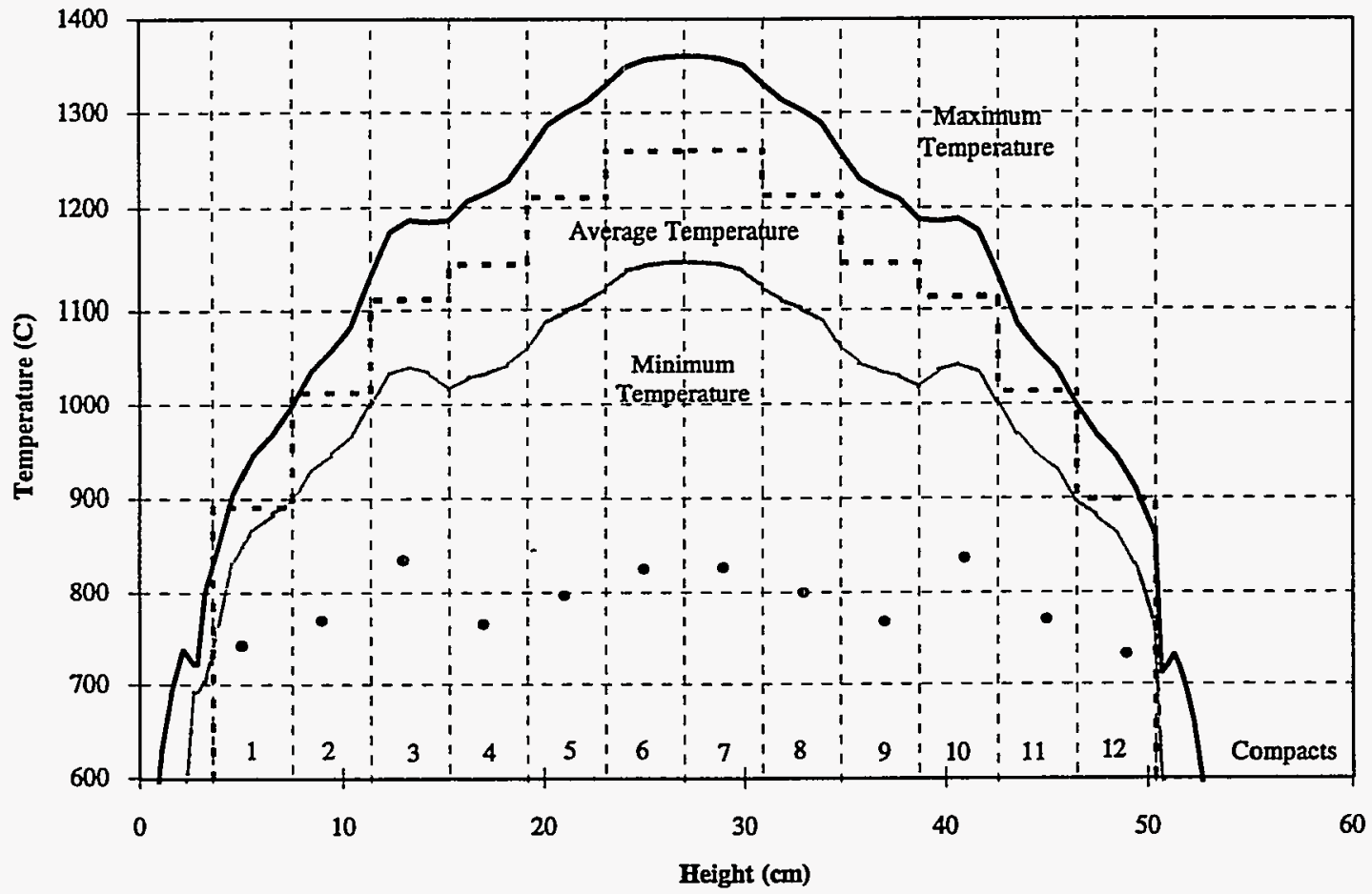

Figure 18. Beginning of Cycle 2 Axial Temperature Distribution

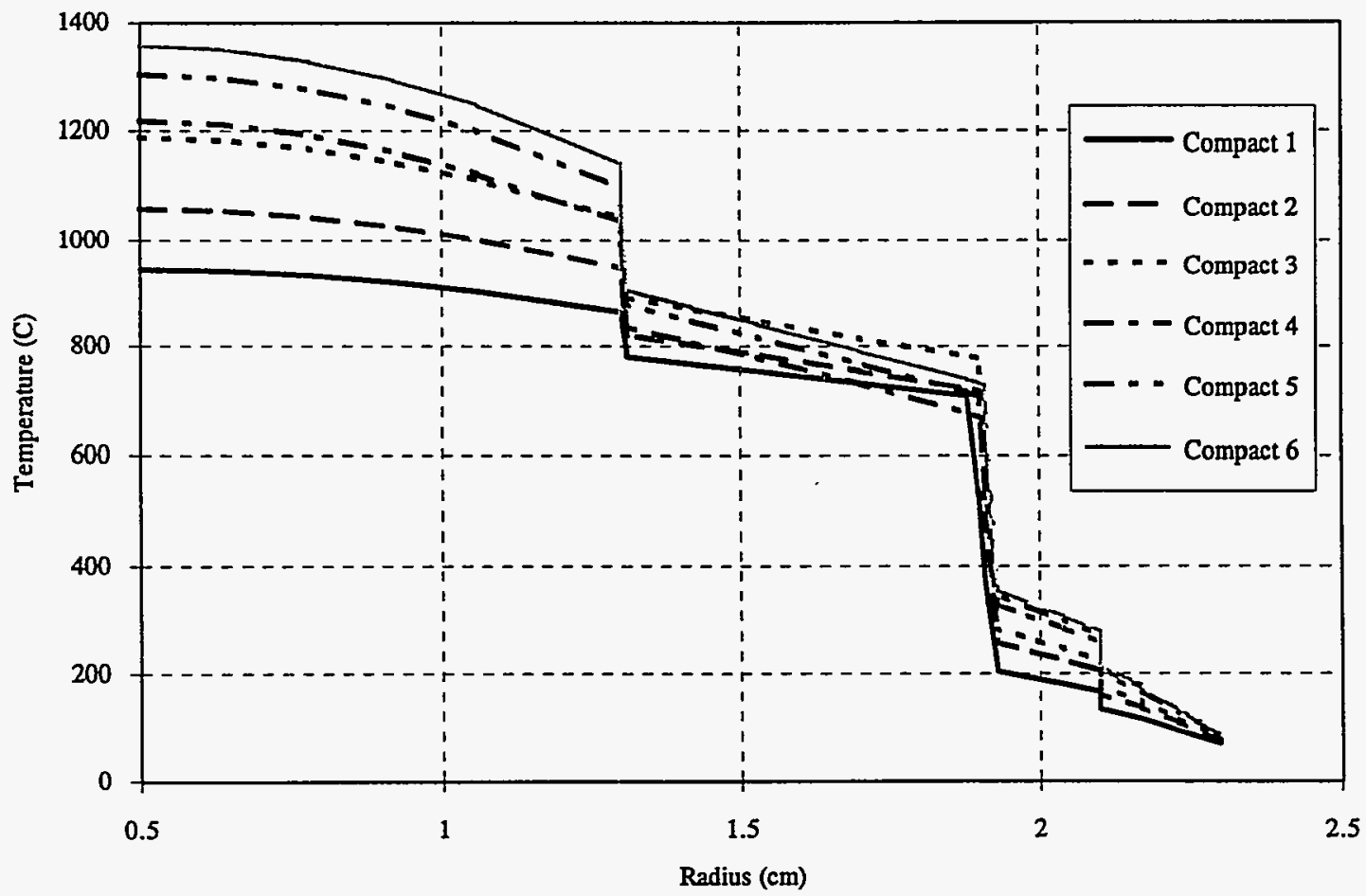

Figure 19. Beginning of Cycle 2 Radial Temperature Distribution 


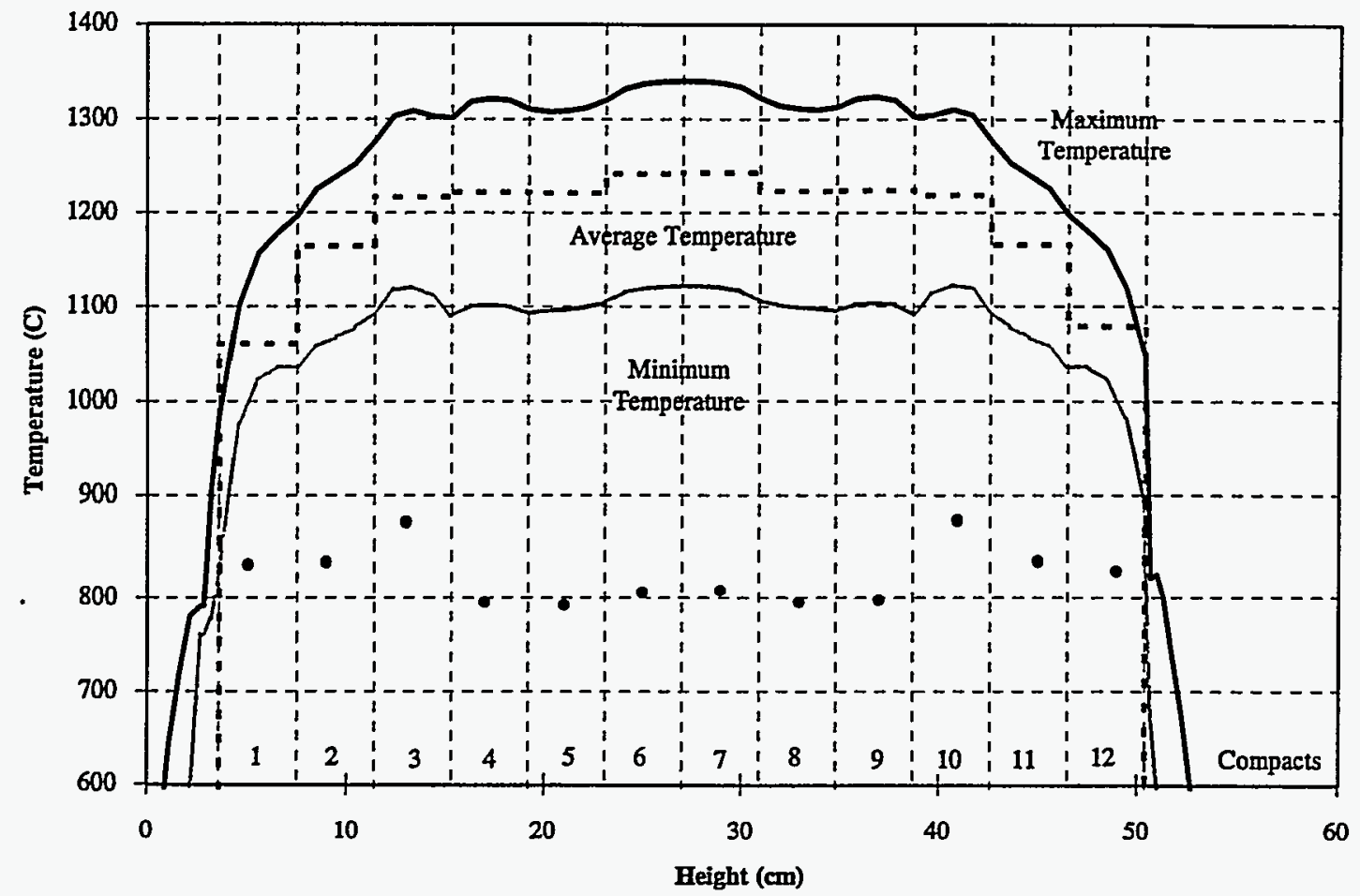

Figure 20. End of Cycle 2 Axial Temperature Distribution

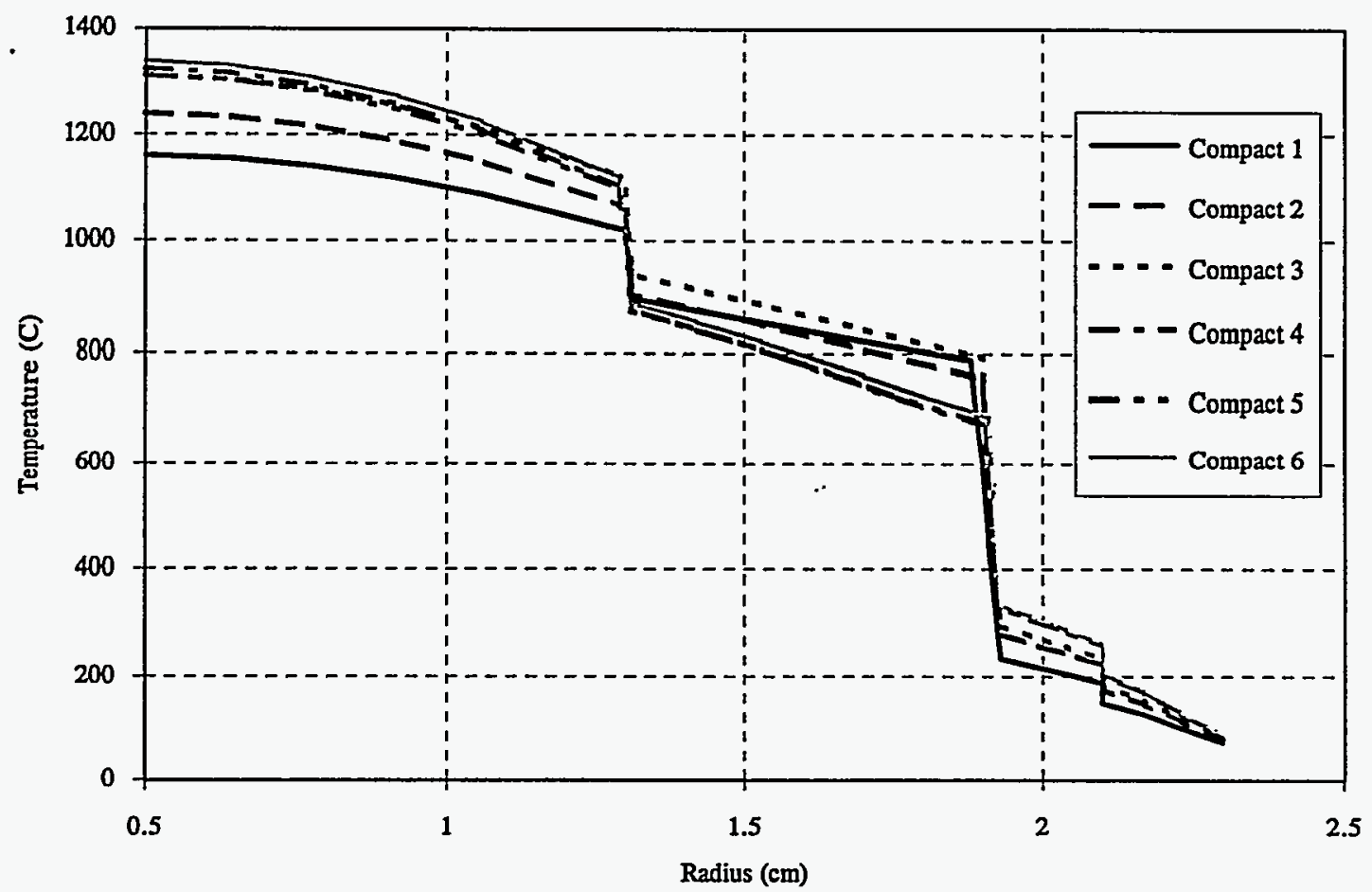

Figure 21. End of Cycle 2 Radial Temperature Distribution 


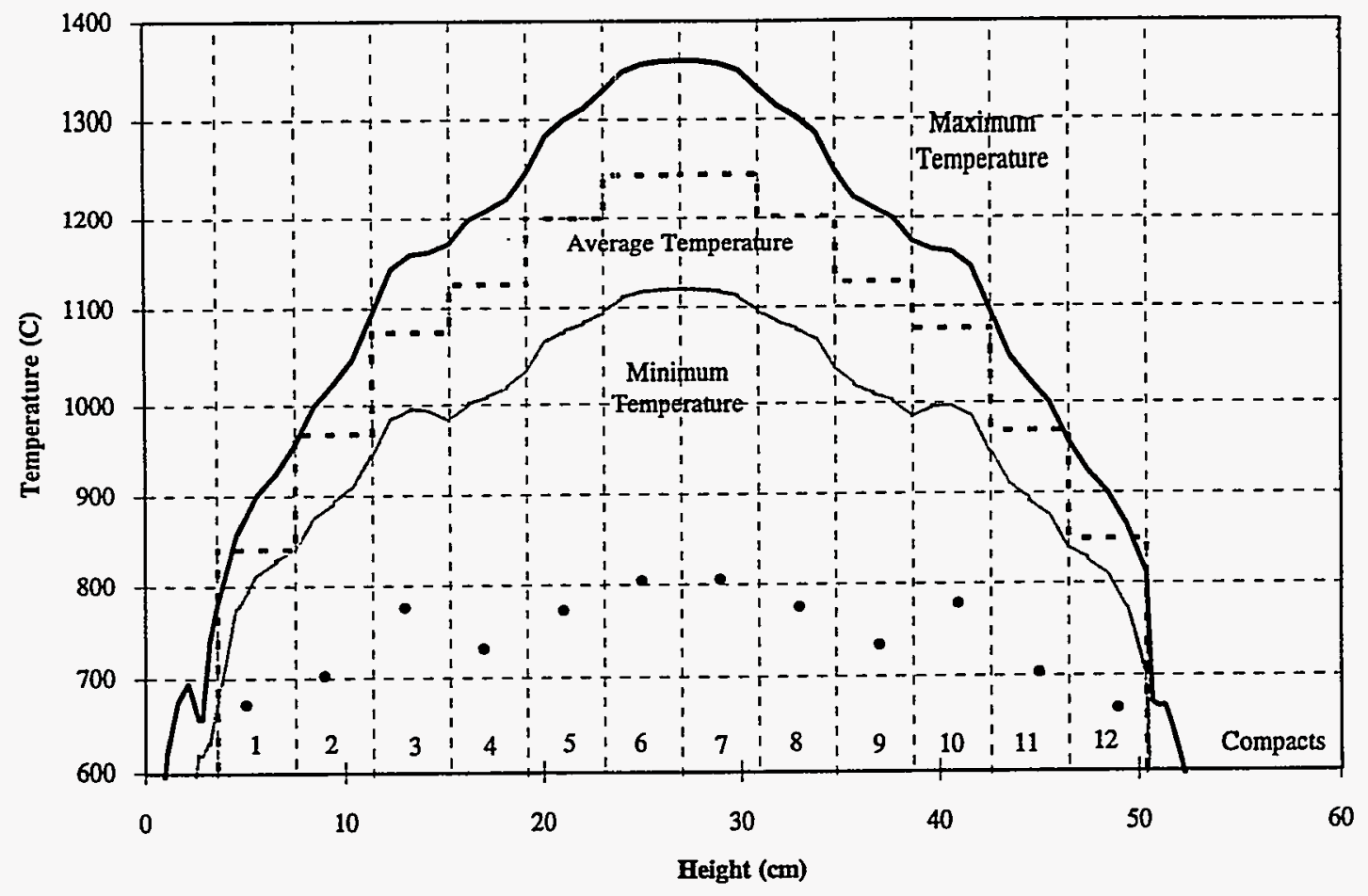

Figure 22. Beginning of Cycle 3 Axial Temperature Distribution

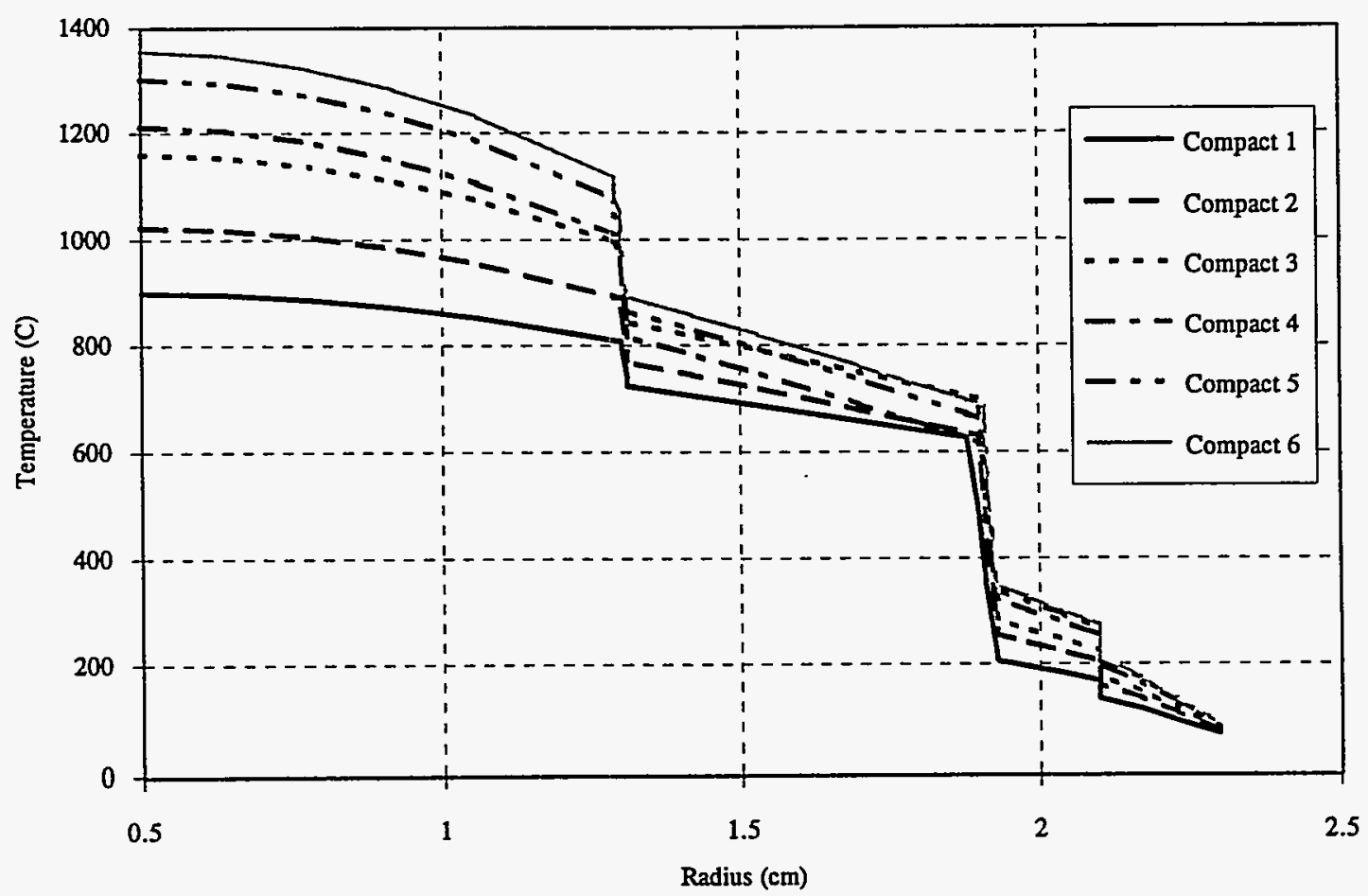

Figure 23. Beginning of Cycle 3 Radial Temperature Distribution 


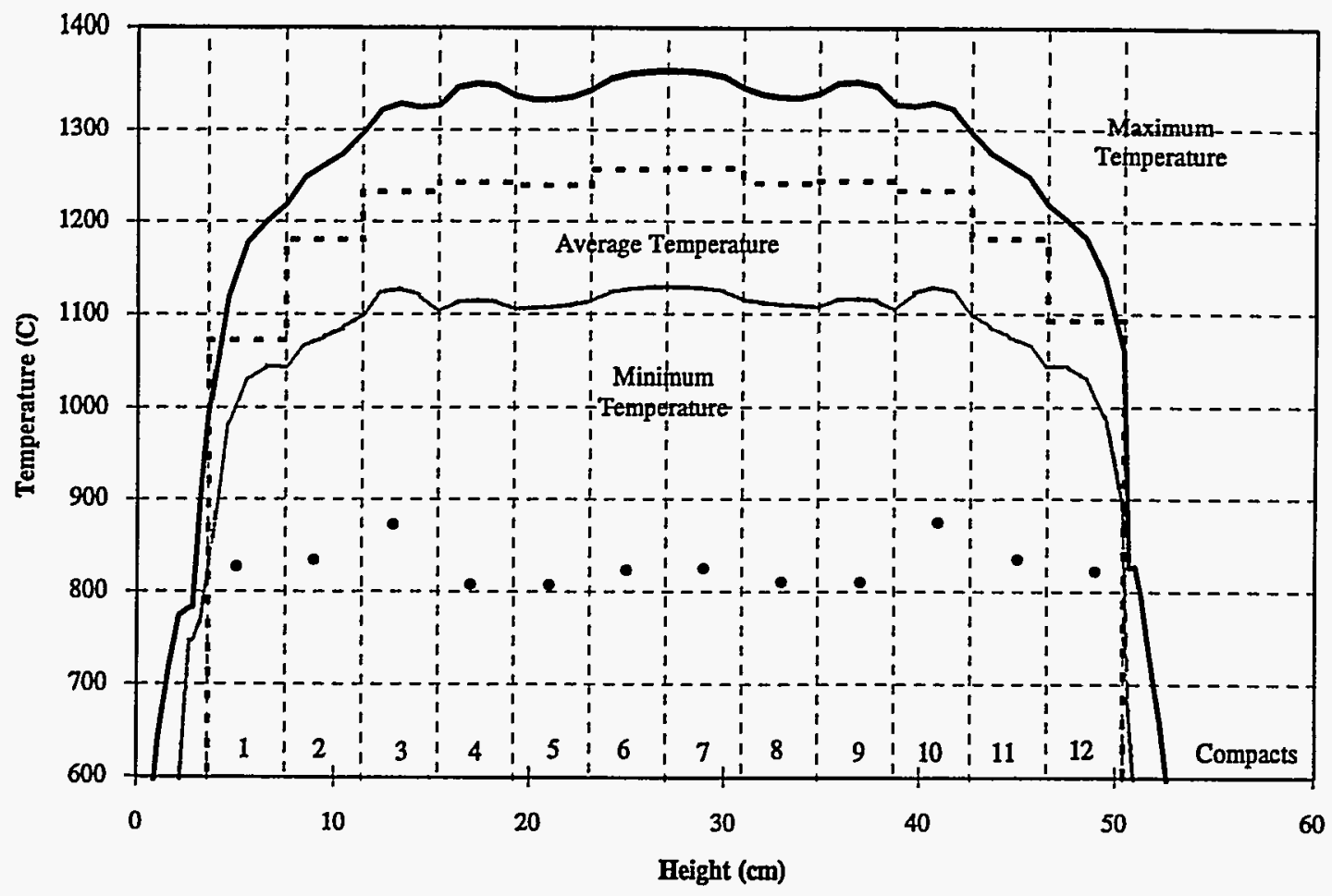

Figure 24. End of Cycle 3 Axial Temperature Distribution

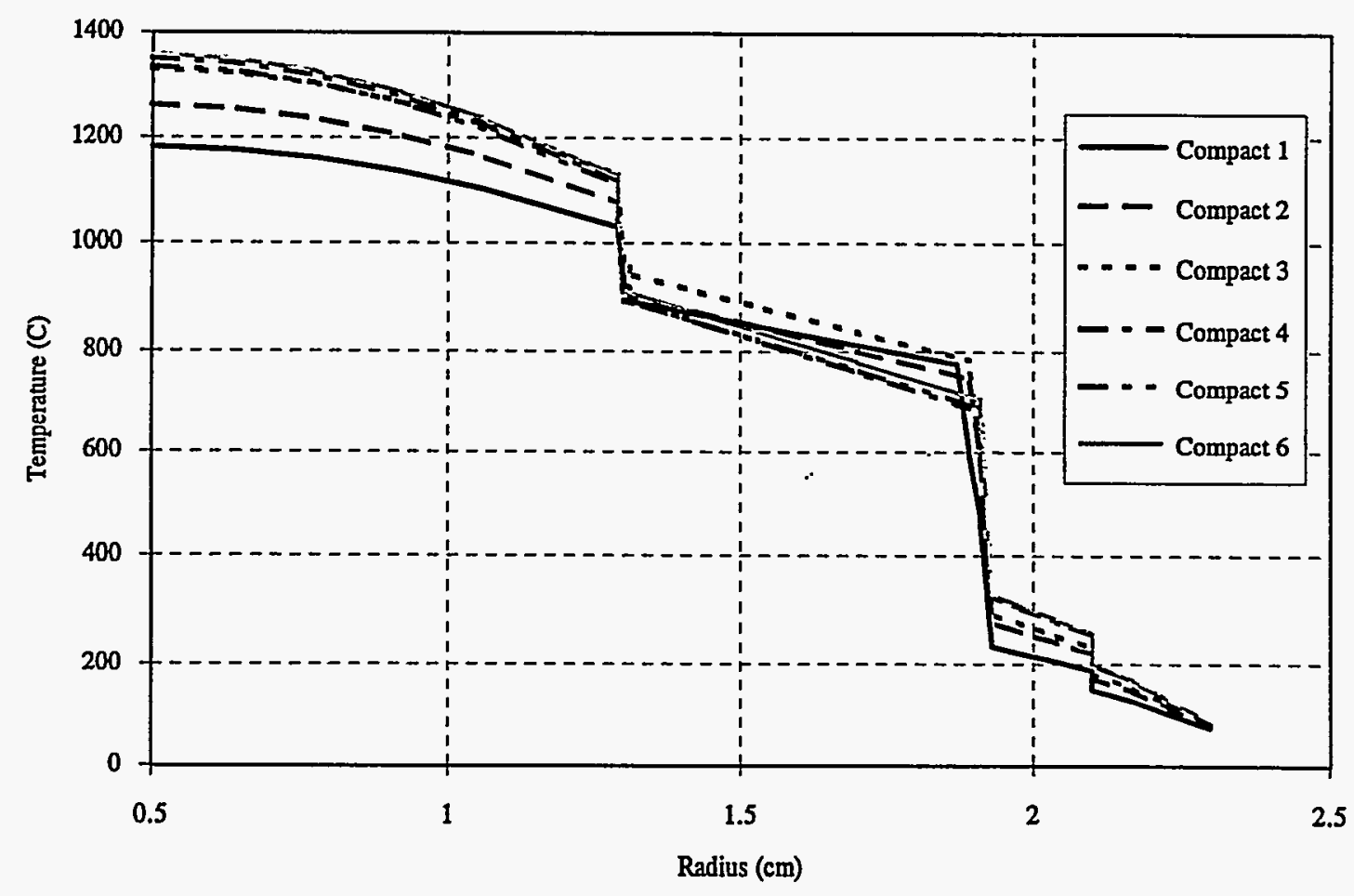

Figure 25. End of Cycle 3 Radial Temperature Distribution 


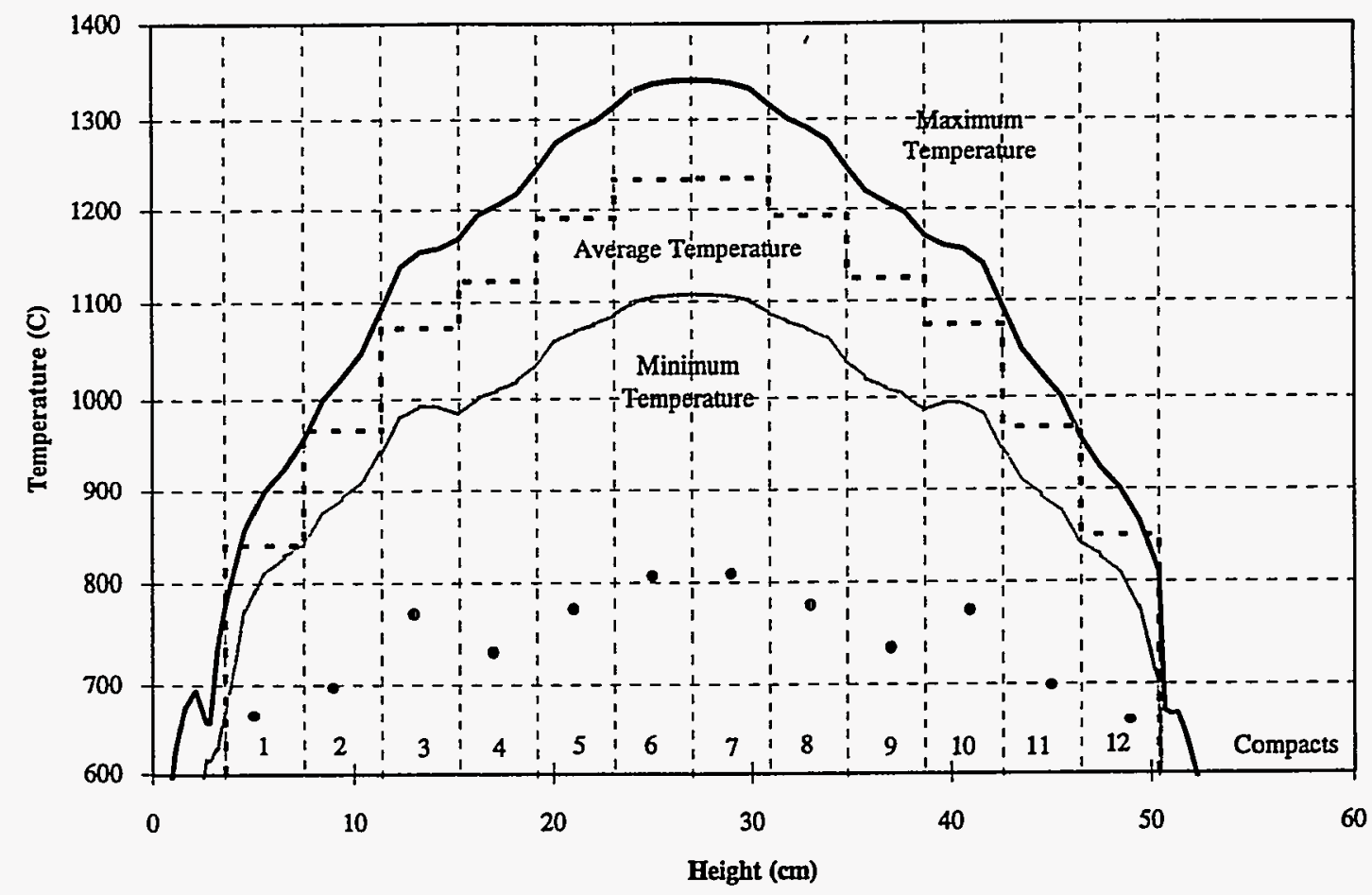

Figure 26. Beginning of Cycle 4 Axial Temperature Distribution

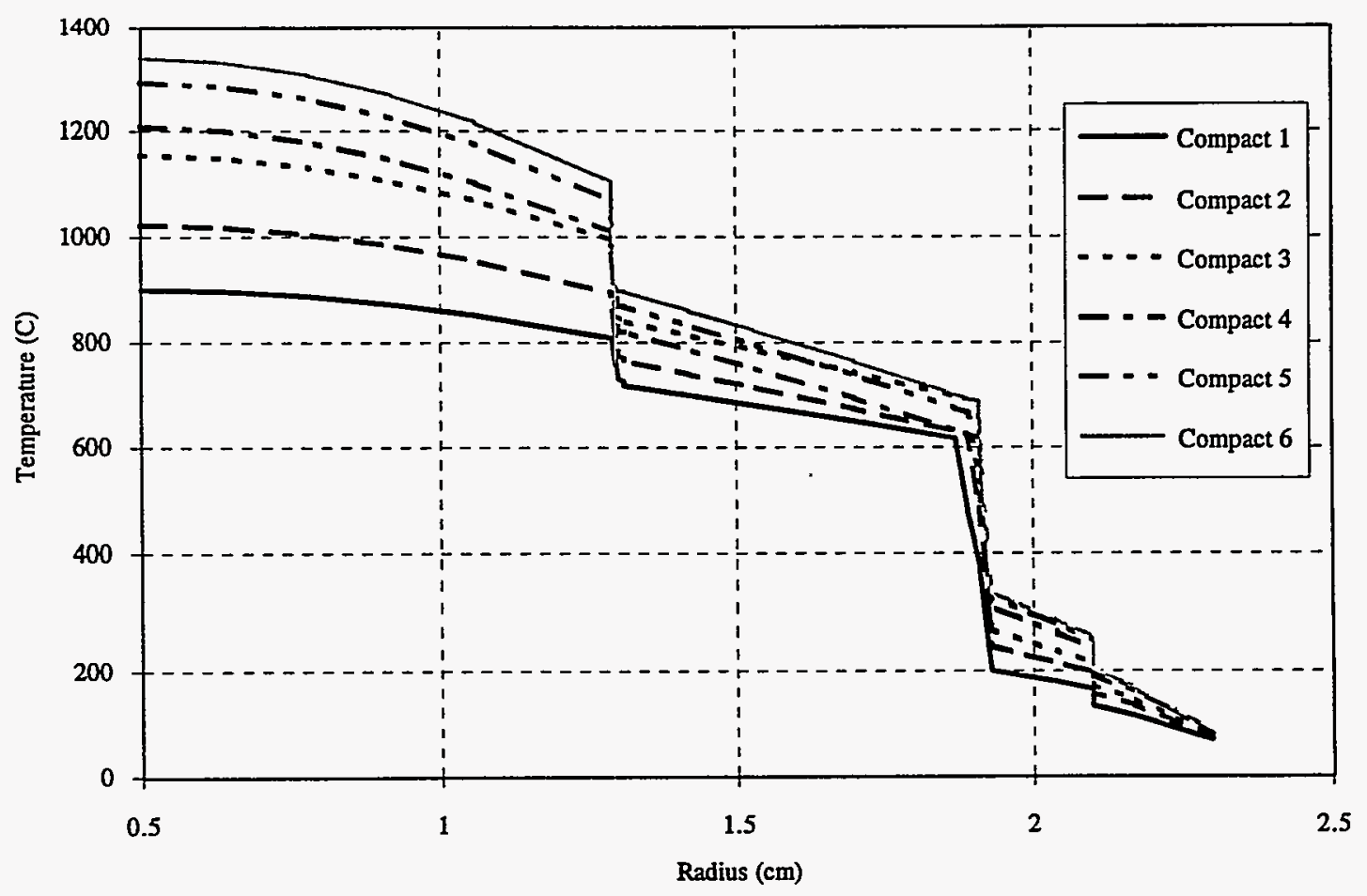

Figure 27. Beginning of Cycle 4 Radial Temperature Distribution 


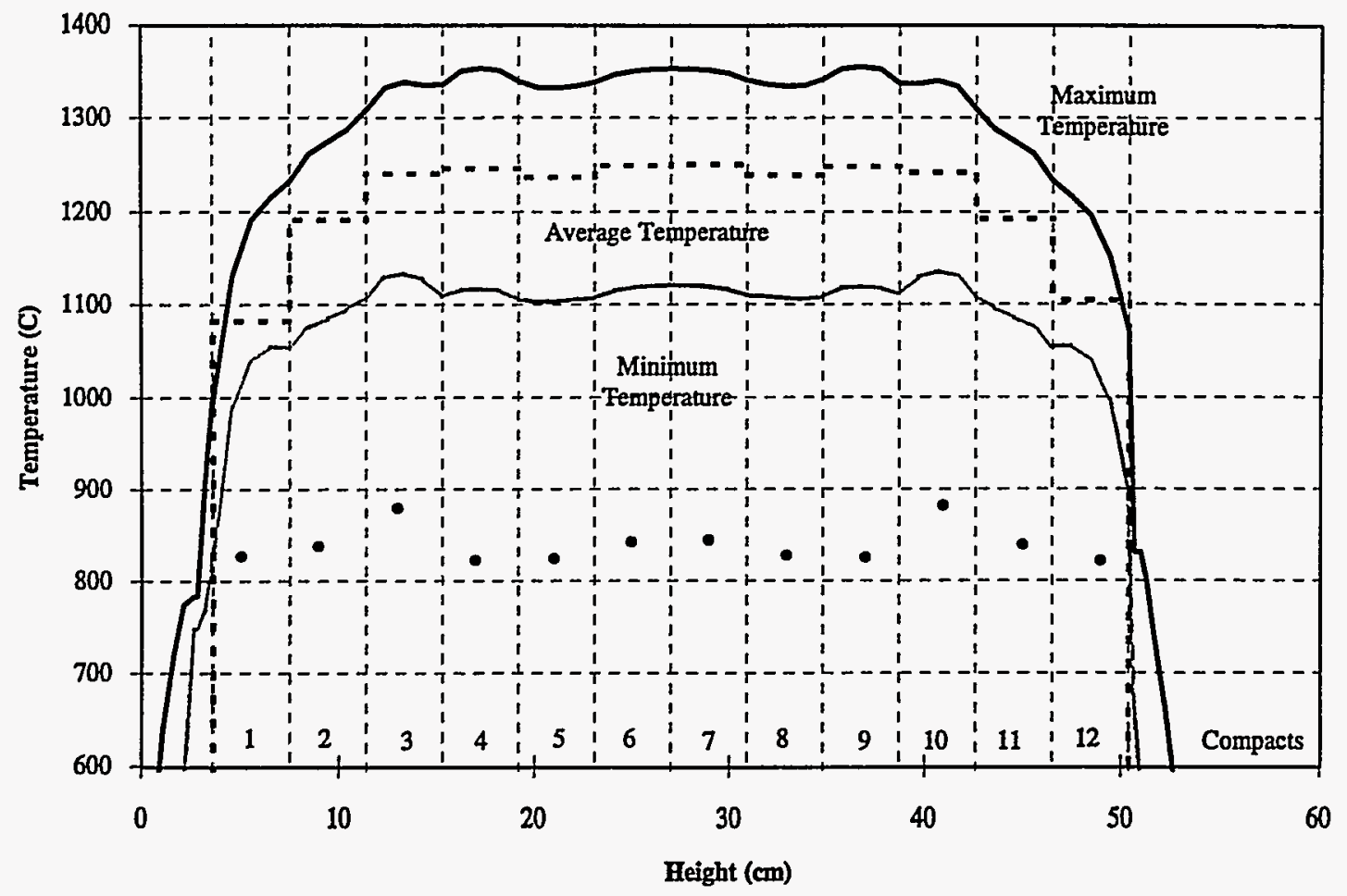

Figure 28. End of Cycle 4 Axial Temperature Distribution

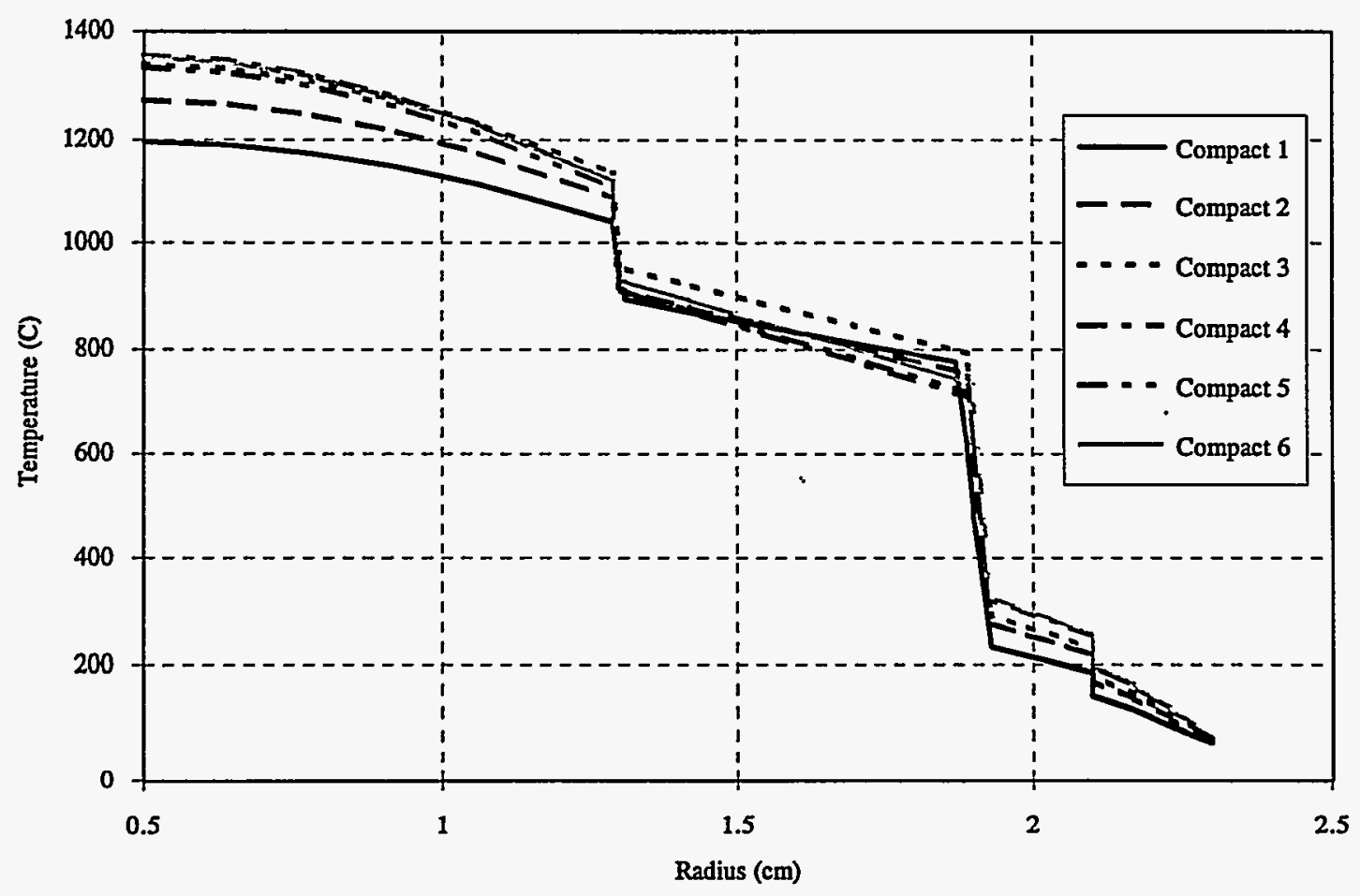

Figure 29. Fnd of Cycle 4 Radial Temperature Distribution 


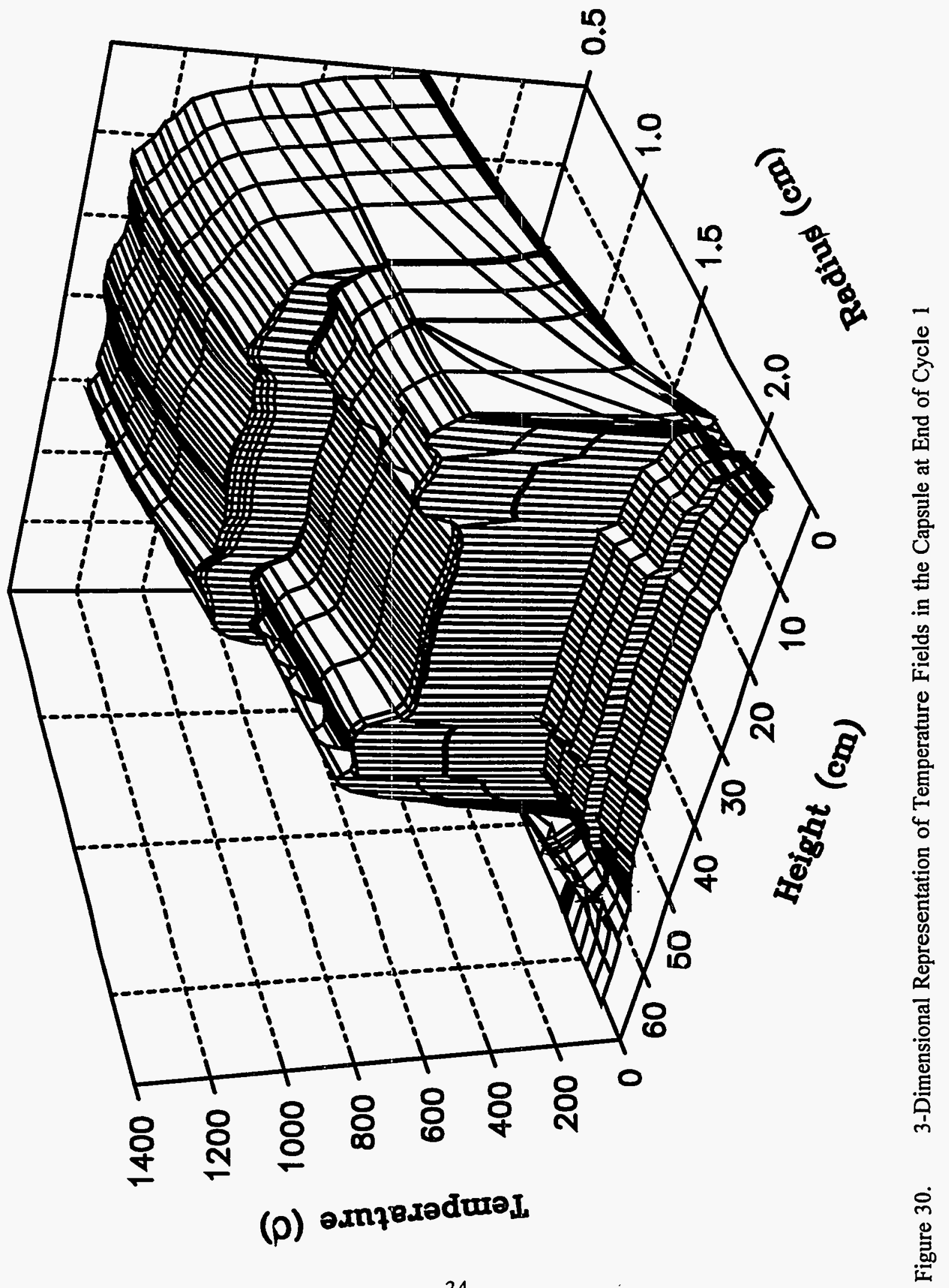




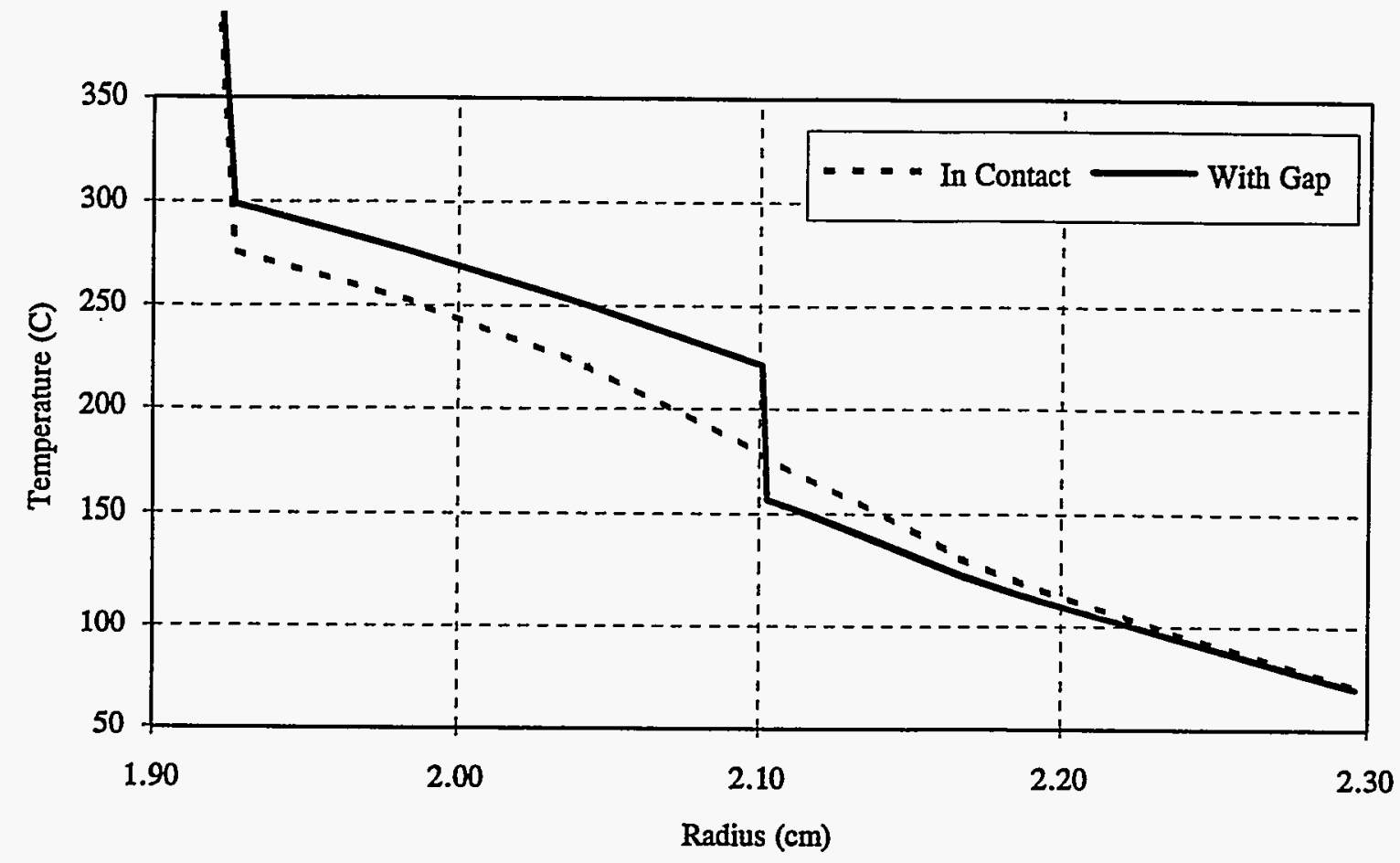

Figure 31. Comparision of temperature profiles through the primary and secondary pressure vessels with and without contact

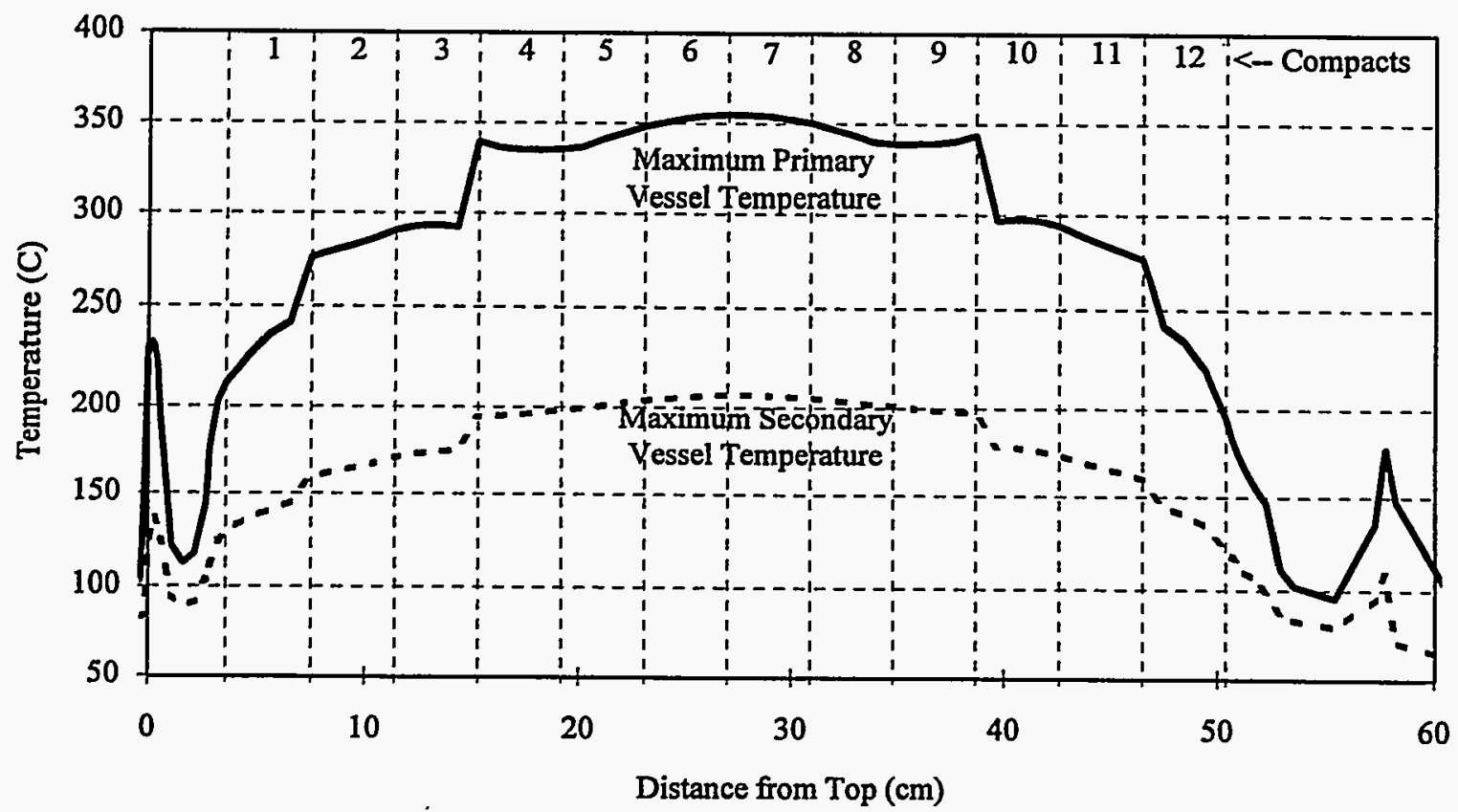

Figure 32. Predicted maximum temperatures of the primary and secondary pressure vessels during the four cycles of irradiation 



\section{INTERNAL DISTRIBUTION}

1-2. Central Research Library

3. Document Reference Section

45. Laboratory Records Department

6. Laboratory Records, ORNL RC

7. ORNL Patent Office

8-10. M\&C Records Office
11. R. W. Hobbs

12. O. F. Kimball

13. R. N. Morris

14. P. L. Rittenhouse

15. K. R. Thoms

\section{EXTERNAL DISTRIBUTION}

16-17. GENERAL ATOMICS CO., P.O. Box 85608, San Diego, CA 92186-9784

R. Acharya

F. C. Montgomery

18. JAPAN ATOMIC ENERGY RESEARCH INSTITUTE, Tokai-mura, Ibaraki-ken, 319-11, Japan

K. Fukuda

19. JAPAN ATOMIC ENERGY RESEARCH INSTITUTE, Department of HTTR Project, Oarai Research Establishment, Oarai-machi, Higashiibaraki-gun, Ibaraki-ken, 311-13, Japan

K. Sawa

20. DEPARTMENT OF ENERGY, OAK RIDGE OPERATIONS OFFICE, P.O.

Box 2001, Oak Ridge, TN 37831-8600

Assistant Manager for Energy Research and Development

21-22. DEPARTMENT OF ENERGY, OFFICE OF SCIENTIFIC AND TECHNICAL

INFORMATION, Office of Information Services, P.O. Box 62, Oak Ridge, TN 37831

For distribution by microfiche as shown in

TIC-4500, Distribution Category UC-522

(Gas-Cooled Reactor Technology). 